Washington University School of Medicine Digital Commons@Becker

Open Access Publications

2016

\title{
Dickkopf-related protein 1 (Dkk1) regulates the accumulation and function of myeloid derived suppressor cells in cancer
}

\author{
Lucia D'Amico \\ Washington University School of Medicine in St. Louis \\ Sahil Mahajan \\ Washington University School of Medicine in St. Louis \\ Aude-Helene Capietto \\ Washington University School of Medicine in St. Louis \\ Zhengfeng Yang \\ Washington University School of Medicine in St. Louis \\ Ali Zamani \\ Washington University School of Medicine in St. Louis
}

See next page for additional authors

Follow this and additional works at: https://digitalcommons.wustl.edu/open_access_pubs

Please let us know how this document benefits you.

\section{Recommended Citation}

D'Amico, Lucia; Mahajan, Sahil; Capietto, Aude-Helene; Yang, Zhengfeng; Zamani, Ali; Ricci, Biancamaria; Bumpass, David B.; Meyer, Melissa; Su, Xinming; Wang-Gillam, Andrea; Weilbaecher, Katherine; Stewart, Sheila A.; DeNardo, David G.; and Faccio, Roberta, "Dickkopf-related protein 1 (Dkk1) regulates the accumulation and function of myeloid derived suppressor cells in cancer." The Journal of Experimental Medicine. 213, 5. 827-40. (2016).

https://digitalcommons.wustl.edu/open_access_pubs/6104

This Open Access Publication is brought to you for free and open access by Digital Commons@Becker. It has been accepted for inclusion in Open Access Publications by an authorized administrator of Digital Commons@Becker. For more information, please contact vanam@wustl.edu. 


\section{Authors}

Lucia D'Amico, Sahil Mahajan, Aude-Helene Capietto, Zhengfeng Yang, Ali Zamani, Biancamaria Ricci, David B. Bumpass, Melissa Meyer, Xinming Su, Andrea Wang-Gillam, Katherine Weilbaecher, Sheila A. Stewart, David G. DeNardo, and Roberta Faccio 


\title{
Dickkopf-related protein 1 (Dkk1) regulates the accumulation and function of myeloid derived suppressor cells in cancer
}

\author{
Lucia D’Amico, ${ }^{1}$ Sahil Mahajan, ${ }^{1}$ Aude-Hélène Capietto, ${ }^{1}$ Zhengfeng Yang, ${ }^{1}$ Ali Zamani, ${ }^{1}$ \\ Biancamaria Ricci, ${ }^{1}$ David B. Bumpass, ${ }^{1}$ Melissa Meyer, ${ }^{2}$ Xinming Su, ${ }^{2}$ Andrea Wang-Gillam, ${ }^{2}$ \\ Katherine Weilbaecher, ${ }^{2,4}$ Sheila A. Stewart, ${ }^{3,4,5}$ David G. DeNardo, ${ }^{2,4,5}$ and Roberta Faccio ${ }^{1,4}$
}

'Department of Orthopedics, ${ }^{2}$ Department of Medicine Oncology Division, ${ }^{3}$ Department of Cell Biology and Physiology, ${ }^{4}$ Siteman Cancer Center, and ${ }^{5}$ ICCE Institute, Washington University School of Medicine, St. Louis, M0 63110

Tumor-stroma interactions contribute to tumorigenesis. Tumor cells can educate the stroma at primary and distant sites to facilitate the recruitment of heterogeneous populations of immature myeloid cells, known as myeloid-derived suppressor cells (MDSCs). MDSCs suppress T cell responses and promote tumor proliferation. One outstanding question is how the local and distant stroma modulate MDSCs during tumor progression. Down-regulation of $\beta$-catenin is critical for MDSC accumulation and immune suppressive functions in mice and humans. Here, we demonstrate that stroma-derived Dickkopf-1 (Dkk1) targets $\beta$-catenin in MDSCs, thus exerting immune suppressive effects during tumor progression. Mice bearing extraskeletal tumors show significantly elevated levels of Dkk1 in bone microenvironment relative to tumor site. Strikingly, Dkk1 neutralization decreases tumor growth and MDSC numbers by rescuing $\beta$-catenin in these cells and restores T cell recruitment at the tumor site. Recombinant Dkk1 suppresses $\beta$-catenin target genes in MDSCs from mice and humans and anti-Dkk1 loses its antitumor effects in mice lacking $\beta$-catenin in myeloid cells or after depletion of MDSCs, demonstrating that Dkk1 directly targets MDSCs. Furthermore, we find a correlation between $\mathrm{CD}_{1} 5^{+}$myeloid cells and Dkk1 in pancreatic cancer patients. We establish a novel immunomodulatory role for Dkk1 in regulating tumor-induced immune suppression via targeting $\beta$-catenin in MDSCs.

Incipient tumor cells that escape intrinsic cellular mechanisms of tumor suppression require support from the surrounding stroma for their growth and ability to metastasize. The tumor-associated stroma provides vascular support and protumorigenic factors that can sustain tumor cell growth (Räsänen and Vaheri, 2010; Barcellos-Hoff et al., 2013). Similarly, at metastatic sites, such as in the bone microenvironment, tumor-activated osteoclasts and osteoblasts release bone-derived factors that favor tumor colonization and proliferation (Weilbaecher et al., 2011). In addition to direct effects on tumor cells, the stromal compartment at primary and distal sites can indirectly contribute to tumor progression by supporting the development of an immunosuppressive environment that facilitates tumor escape from immune control (Mace et al., 2013).

Cytotoxic T cells are central players in immune-mediated control of cancer, and the extent of tumor infiltration by cytotoxic $\mathrm{T}$ cells correlates with a favorable prognosis (Galon et al., 2006; Hamanishi et al., 2007; Mahmoud et al., 2011; Bindea et al., 2013). However, this natural defense mechanism can be severely blunted by immunosuppressive cell populations, includ-

Correspondence to Roberta Faccio: faccior@wustl.edu

Abbreviations used: Dkk1, Dickkopf-1; IHC, immunohistochemistry; LLC, Lewis lung carcinoma; LysM, Lysozyme M; MDSC, myeloid-derived suppressor cell; NO, nitric oxide; ROS, reactive oxygen species; TMA, tissue microarray. ing regulatory $\mathrm{T}$ cells and myeloid suppressor cells (Schreiber et al., 2011; Gabrilovich et al., 2012). Among myeloid populations with a potent ability to suppress antitumor $\mathrm{T}$ cell responses, myeloid-derived suppressor cells (MDSCs) are found in high numbers in circulation and in the tumor microenvironment of patients with advanced malignancies (Gabitass et al., 2011). MDSCs comprise a heterogeneous population of immature $\mathrm{Gr}^{+} / \mathrm{CD} 11 \mathrm{~b}^{+}$cells in mice and $\mathrm{CD} 33^{+} / \mathrm{CD} 11 \mathrm{~b}^{+}$in humans (Gabrilovich et al., 2012). This myeloid population is further classified into granulocytic or monocytic MDSCs based on the expression levels of Ly6G and Ly6C, respectively, in the mouse model or CD15 and CD14 in humans.

Investigations into the mechanisms that drive MDSC recruitment and activity have shown that GM-CSF, IL-6, and VEGF play an important role via modulation of Jak-STAT signaling pathways (Gabrilovich et al., 2001; Trikha and Carson, 2014). In addition to Jak-STAT, we have recently shown that down-regulation of $\beta$-catenin in MDSCs is required for their accumulation during tumor progression in mice and cancer patients (Capietto et al., 2013). Specific deletion of $\beta$-catenin in myeloid cells leads to greater s.c. tumor growth due to the accumulation and higher immune suppressive ef-

2016 D'Amico et al. This article is distributed under the terms of an Attribution-Noncommercial-Share

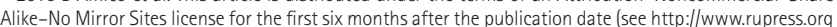
Alike-No Mirror Sites license for the first six months after the publication date (see http://www.rupress.org
/terms). After six months it is available under a Creative Commons License (Attribution-NoncommercialShare Alike 3.0 Unported license, as described at http://creativecommons.org/licenses/by-nc-sa/3.0/). 
fects of MDSCs. Conversely, $\beta$-catenin stabilization in myeloid cells limits tumor growth by limiting MDSC numbers and their $\mathrm{T}$ cell suppressive function (Capietto et al., 2013). However, an outstanding question in the field is how $\beta$-catenin is down-regulated in MDSCs during tumor progression and whether the tumor-associated stromal compartment plays a role in this process.

Dickkopf-1 (Dkk1) is an inhibitor of the Wnt- $\beta$-catenin pathway (MacDonald et al., 2009). It competitively binds to the Wnt co-receptors LRP5/6, leading to degradation of the $\beta$-catenin complex. High circulating levels of Dkk1 correlate with poor prognosis in various cancers (Liu et al., 2014). In the context of multiple myeloma (MM), Dkk1, produced by the cancer cells and bone marrow stromal cells, inhibits osteoblast maturation while enhancing osteoclast resorption (Tian et al., 2003; Fowler et al., 2012). These effects of Dkk1 on the bone microenvironment contribute to the development of focal osteolytic lesions and indirectly favor MM progression. Increased levels of Dkk1 are also found in serologic samples from patients with cancer of the pancreas, stomach, liver, lung, esophagus, and breast, regardless of the presence of metastatic dissemination to bone (Yamabuki et al., 2007; Liu et al., 2014). These observations suggest more pleiotropic effects of Dkk1 in controlling tumor growth, independent of its ability to alter the bone microenvironment. Furthermore, down-regulation of $\beta$-catenin in cancerous cells should reduce their proliferative capacity. Therefore, it remains to be established why increased levels of Dkk1 correlate with poor prognosis.

We now provide evidence that Dkk1 supports the generation of MDSCs, and thus is a negative regulator of antitumor immune responses. Importantly, we show that Dkk1 neutralization decreases tumor growth and MDSC accumulation in extraskeletal tumor models. To our knowledge, this is the first demonstration that Dkk1 supports extraskeletal tumor growth by creating an immunosuppressive environment through direct targeting of $\beta$-catenin in MDSCs.

\section{RESULTS \\ Dkk1 is up-regulated in the bone microenvironment of mice bearing extraskeletal tumors}

We have recently shown that down-regulation of $\beta$-catenin levels in MDSCs occurs in tumor-bearing mice and cancer patients. Reductions in $\beta$-catenin drive MDSC accumulation in the bone marrow, spleen, and at primary tumor sites, and control their immune suppressive effects (Capietto et al., 2013). To elucidate the mechanism(s) responsible for reduced $\beta$-catenin levels in MDSCs during tumor progression we measured the circulating levels of the $\mathrm{Wnt} / \beta$-catenin inhibitor Dkk1, because it has been associated with poor prognosis in various types of cancer (Liu et al., 2014). C57BL/6 WT mice were s.c. injected with $10^{5}$ Lewis lung carcinoma (LLC) cells and serum was collected $0,7,10$, and 14 d later. We found that circulating Dkk1 levels increased 20-fold, paralleling tumor progression (Fig. $1 \mathrm{~A}$ ).
Next, we wanted to determine the source of Dkk1 in tumor-bearing mice. Surprisingly, immunohistochemistry (IHC) analysis of LLC tumors revealed a weak and diffuse Dkk1 staining compared with pancreatic islets from mice with pancreatic adenocarcinomas, which we used as a positive control, or the ductal epithelium and stroma, which were negative and thus used as internal negative control (Fig. 1 B). This result was unexpected, given the significant increase in Dkk1 in circulation (Fig. $1 \mathrm{~A}$ ), and prompted us to investigate other sources of Dkk1 in the LLC tumor-bearing mice.

Dkk1 is highly expressed in the bone microenvironment by osteoblasts and osteocytes to regulate bone homeostasis (Li et al., 2006; Pinzone et al., 2009). Because MDSCs originate and accumulate in the bone microenvironment during tumor progression, we wondered whether Dkk1 levels would be increased in bones from tumor-bearing mice. First, we measured by quantitative RT-PCR Dkk1 transcripts in crushed bones devoid of bone marrow cells (as a source of osteoblasts and osteocytes), and in the bone marrow cells from LLC tumor-bearing mice. LLC tumors in vivo from the same cohort of mice and LLC cells cultured in vitro were used as controls. Confirming the IHC data, the LLC cell line did not express detectable Dkk1 transcripts. Strikingly, Dkk1 mRNA levels in the crushed bones (devoid of marrow cells) were $\sim 500$-fold higher compared with the tumor mass and the bone marrow cells (Fig. $1 \mathrm{C}$ ), suggesting that osteoblasts and osteocytes are a major source of Dkk1 in tumor-bearing mice. Because Dkk1 is a secreted protein, we measured Dkk1 protein levels in the bone marrow interstitial fluid from LLC tumor-bearing mice by ELISA to further confirm increased expression of bone-derived Dkk1 during tumor progression. We found a significant increase in bone-derived Dkk1 compared with no tumor controls (Fig. 1 D).

To determine whether production of Dkk1 by the bone microenvironment is observed in other tumors, we turned to the B16 melanoma model, as $\beta$-catenin is also down-regulated in MDSCs from B16 tumor-bearing mice. Similar to mice bearing LLC tumors, increased Dkk1 levels were observed in circulation (Fig. 1 E) and in the bone microenvironment (Fig. 1, F and G) of animals injected s.c. with $10^{5}$ B16 melanoma cells. RT-PCR analysis revealed no detectable Dkk1 expression in the tumor cells, and the transcript levels in the tumor mass in vivo were 340-fold less than in the bone (Fig. $1 \mathrm{~F}$ ).

Finally, we analyzed Dkk1 mRNA expression in the bones of tumor-bearing mice (LLC and B16) versus primary osteoblasts or osteoclasts cultured in vitro (Fig. $1 \mathrm{H}$ ). We found a similar magnitude of expression between crushed bones and osteoblast cultures, whereas no expression was detected in the osteoclasts, suggesting that bone-resident osteoblasts, but not osteoclasts, are a major source of Dkk1 in vivo.

Collectively, these results demonstrate increased levels of Dkk1 in the circulation and in the bone microenvironment in two different tumor models, supporting the hypothesis that Dkk1 might regulate $\beta$-catenin levels in peripheral MDSCs. 

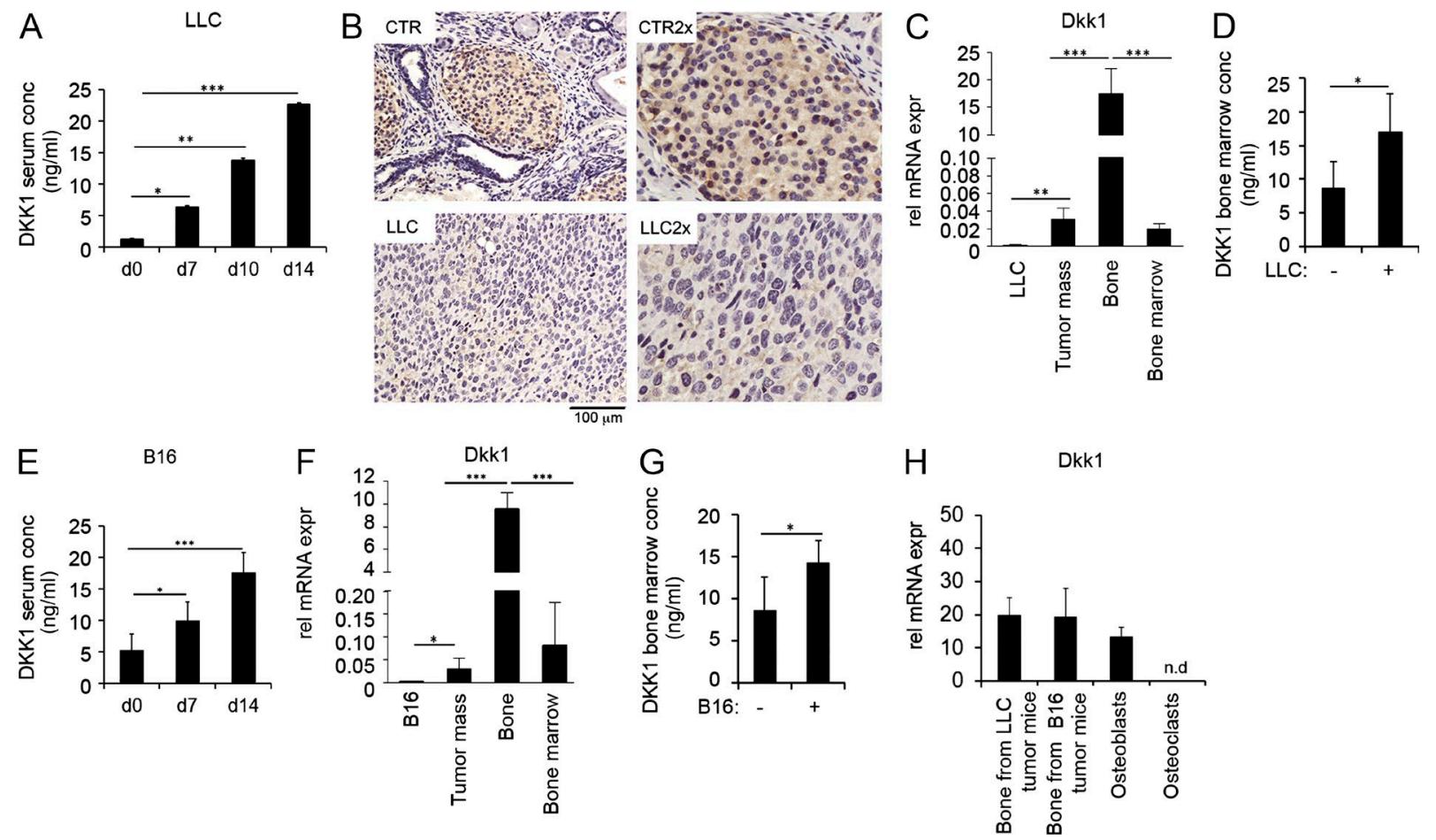

Figure 1. Dkk1 is up-regulated in mice bearing extraskeletal tumors. (A) Dkk1 serum levels were measured by ELISA in WT mice on day 0 or 7,10 , and $14 \mathrm{~d}$ after LLC s.c. injection. $n=4$ per group. ${ }^{*}, \mathrm{P}<0.05 ;{ }^{* *}, \mathrm{P}<0.01 ;{ }^{* * *}, \mathrm{P}<0.001$. Experiment was repeated two times. (B) IHC from mouse pancreatic ductal adenocarcinoma (CTR) or LLC s.c. tumor sections stained for Dkk1. Images are taken with an 20x objective (left) and $2 \times$ magnification is shown on the right. Data are representative of four different tumor sections. (C) Dkk1 mRNA levels were measured in LLC in vitro, LLC tumor mass, crushed bones devoid of marrow cells, and bone marrow cells isolated from WT mice 2 wk after s.c. tumor injection. Data are expressed as relative expression to cyclophillin. Results represent mean \pm SD ( $n=6$, experiment repeated three times). ${ }^{* *}, P<0.01 ;{ }^{* * *}, P<0.001$. (D) Dkk1 levels in the bone marrow interstitial fluid of LLC tumor-bearing mice versus no tumor controls collected 2 wk after s.c. tumor injection. ${ }^{*}, P<0.05 . n=6$. Experiment was performed in duplicate. (E) Dkk1 levels in circulation from WT mice prior, 7, or $14 \mathrm{~d}$ after s.c. inoculation of $10^{5} \mathrm{~B} 16$ cells. ${ }^{*}, \mathrm{P}<0.05$; $^{* * *}, \mathrm{P}<0.001 . n=5$. Experiment performed in duplicate. (F) Dkk1 mRNA levels were measured in B16 cell line, tumor mass, crushed bones devoid of bone marrow cells, and in the bone marrow $14 \mathrm{~d}$ after B16 s.c. tumor injection. ${ }^{*}, P<0.05 ;{ }^{* * *}, P<0.001 . n=5$. Experiment was repeated more than three times. $(G) D k k 1$ levels in the bone marrow interstitial fluid from WT mice prior and $14 \mathrm{~d}$ after s.c inoculation of $10^{5} \mathrm{~B} 16$ cells. ${ }^{*}, \mathrm{P}<0.05 . n=6$. Experiment was performed in duplicate. (H) Dkk1 mRNA levels were measured in crushed bones separated from the bone marrow of mice inoculated s.c. with LLC or B16 for $14 \mathrm{~d}$, in osteoblast cultures and primary osteoclasts. $n=3$. Experiment was repeated three times.

\section{Dkk1 directly targets $\beta$-catenin in MDSCs}

Dkk1 antagonizes canonical Wnt signaling by binding to LRP5/6 receptors and inhibiting their interaction with Wnt ligands. To evaluate whether Dkk1 can directly target MDSCs, we first measured LRP5 and LRP6 expression levels in $\mathrm{Gr}^{+} / \mathrm{CD} 11 \mathrm{~b}^{+}$cells isolated from tumor naive mice or animals bearing s.c. LLC tumors. Both receptors were highly expressed in MDSCs from tumor-bearing mice compared with control mice (Fig. 2 A). Induction of LRP5 and LRP6 transcripts was also observed in naive $\mathrm{Gr}^{+} / \mathrm{CD} 11 \mathrm{~b}^{+}$ cells cultured in vitro in the presence of $10 \%$ serum from tumor-bearing mice to mimic the in vivo setting (Fig. $2 \mathrm{~B}$ ).

To test whether Dkk1 directly affects $\beta$-catenin protein levels in MDSCs, naive $\mathrm{Gr}^{+} / \mathrm{CD} 11 \mathrm{~b}^{+}$cells were isolated from the bone marrow, cultured as described in the Materials and methods, and stimulated for $3 \mathrm{~h}$ with recombinant Dkk1 (rDkk1; 100 $\mathrm{ng} / \mathrm{ml})$. Because Dkk1 is elevated in the serum of tumor-bearing mice (Fig. $1 \mathrm{~A}$ ), which was added to the culture medium, we also incubated the cells with anti-Dkk1 (100 ng/ml), an exercise that would establish the importance of circulating Dkk1 in regulating $\beta$-catenin. Dkk1 neutralization resulted in increased $\beta$-catenin protein levels in the cells (Fig. $2 \mathrm{C}$ ). In contrast, treatment with rDkk1 reduced $\beta$-catenin protein levels compared with controls (Fig. 2 C). Confirming these findings, quantitative RT-PCR analysis of $\beta$-catenin target genes showed a significant reduction of LEF1,TCF4, and Axin2 mRNA expression levels after rDkk1 stimulation versus untreated controls (Fig. $2 \mathrm{D}$ ).

To determine whether Dkk1 reduces $\beta$-catenin levels in human MDSCs, CD $33^{+}$myeloid cells were isolated from PBMCs obtained from different healthy donors and cultured in the presence of serum from cancer patients with elevated Dkk1 levels. Cells were incubated with anti-Dkk1 or stimulated with rDkk1, and mRNA levels of the $\beta$-catenin target genes TCF4 and LEF1 were measured. Similar to the mouse model, we found that rDkk1 reduced the expression of TCF4 and LEF1 (Fig. 2, E and F), whereas neutralization of Dkk1 

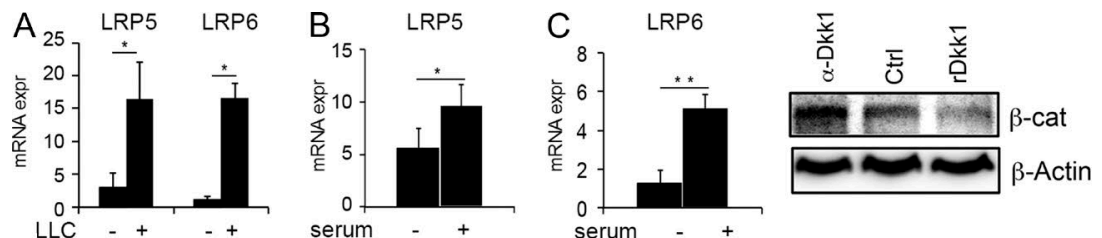

Figure 2. Dkk1 targets $\beta$-catenin in MDSCs and correlates with CD15 myeloid marker. (A and B) LRP5 and LRP6 mRNA expression in MDSCs isolated from LLC tumor-bearing mice $14 \mathrm{~d}$ after tumor injection (A), or in $\mathrm{Gr}^{+} / \mathrm{CD} 11 \mathrm{~b}^{+}$naive cells incubated in vitro in the presence or absence of 10\% serum from tumor-bearing mice (B). Mean $\pm \mathrm{SD}(n=3$ micel group) ${ }^{*}, P<0.05 ;{ }^{* *}, P<0.01$. (C) Western blot analysis of $\beta$-catenin in $\mathrm{Gr}^{+} / \mathrm{CD} 11 \mathrm{~b}^{+}$naive cells cultured for $6 \mathrm{~h}$ in medium containing 10\% serum from tumor-bearing mice in the presence of rDkk1 $100 \mathrm{ng} /$ $\mathrm{ml}$ ) or anti-Dkk1 $(100 \mathrm{ng} / \mathrm{ml})$. One representative experiment of three is shown. (D) LEF1, TCF4, and Axin2 mRNA levels were measured in cells as in B. Mean \pm SD from three independent experiments. ${ }^{*}, \mathrm{P}<0.05$. (E-H) LEF1 and TCF4 mRNA levels were measured in CD33 ${ }^{+}$PBMCs isolated from healthy donors, cultured in the presence of 10\% serum from cancer patients and stimulated in vitro with rDkk1 $(100 \mathrm{ng} / \mathrm{ml} ; \mathrm{E}$ and F) or incubated with anti-Dkk1 (100 ng/ml; $G$ and $H)$. Representative graphs from seven different donors are shown. Experiment was repeated more than three times. (I) Representative IHC from pancreatic cancer tissues with high or low Dkk1 expression is shown. CD15 staining, as a marker of granulocytic MDSCs, is also shown. (J) Correlation between $\mathrm{CD}_{1} 5^{+}$cell numbers and Dkk1 pixel density from 55 pancreatic cancer tissues is shown (Spearman's $r=0.27 ; P=0.04$ ).

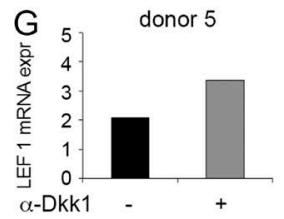
rDkk1:

rDkk1:
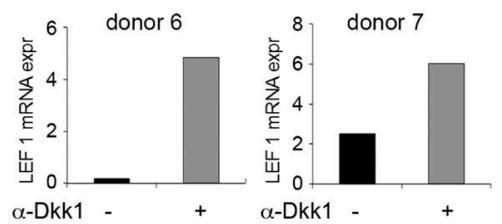

rDkk1:
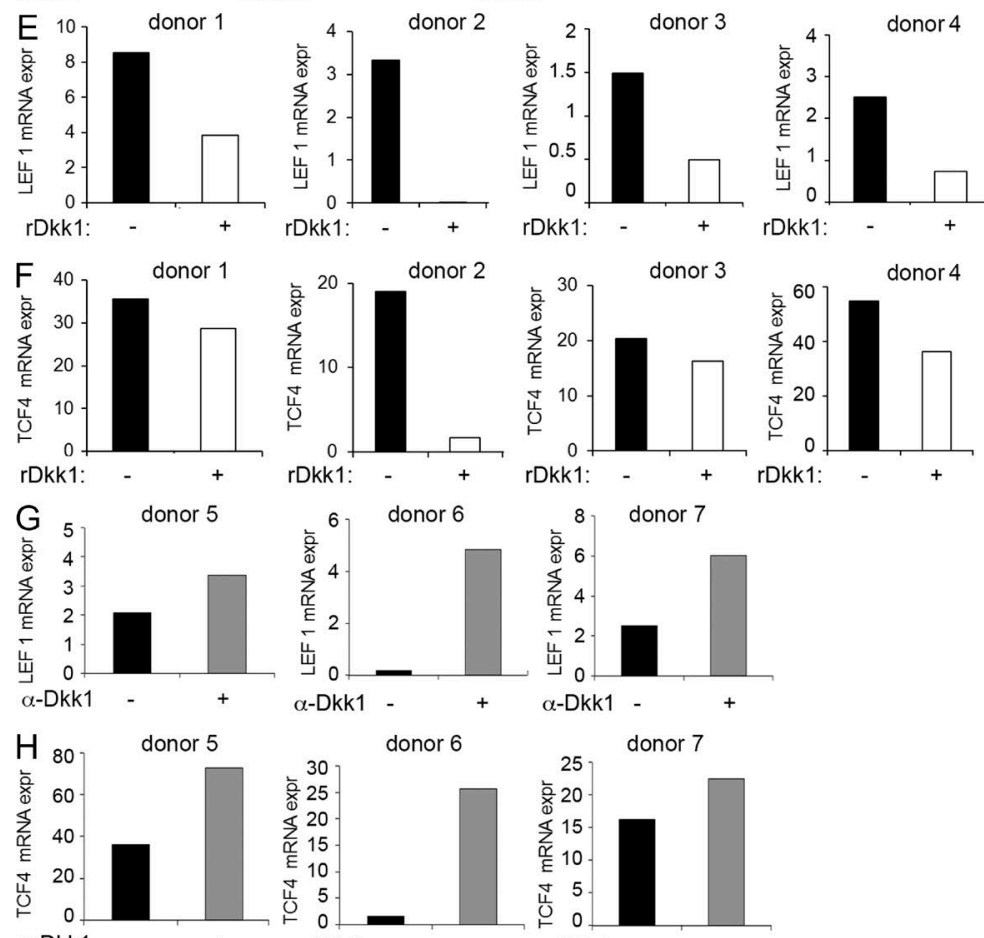

$\alpha$-Dkk1 -

$\alpha$-Dkk1 -
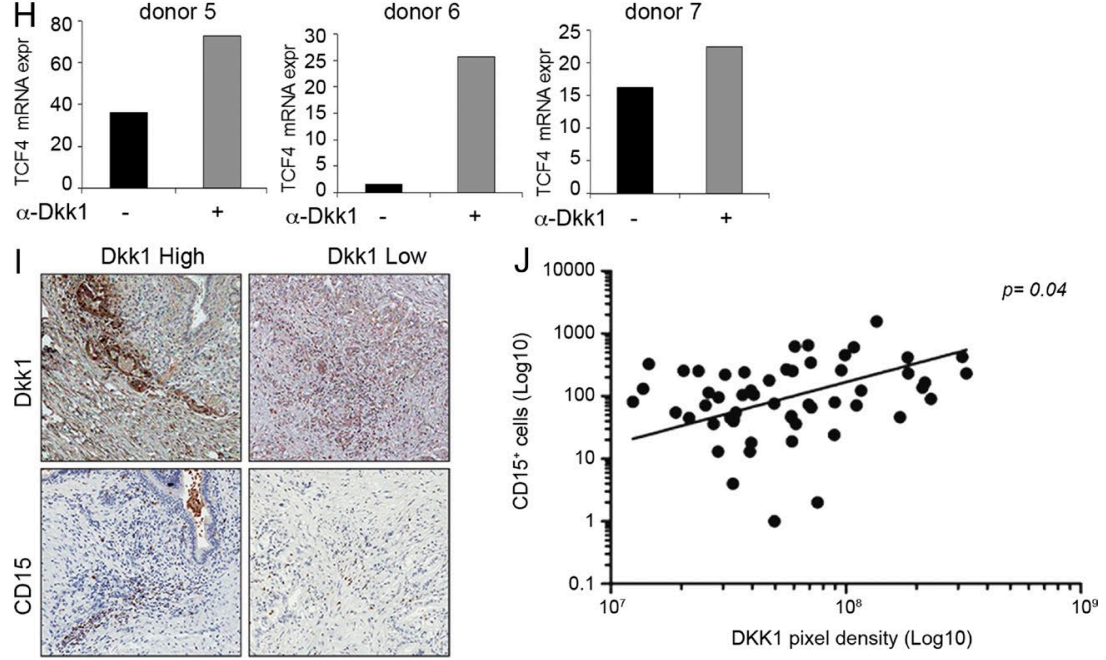

resulted in the up-regulation of the two $\beta$-catenin target genes in human cells (Fig. 2, G and H). Thus, Dkk1 inhibits the $\beta$-catenin pathway both in mouse and human MDSCs.

Dkk1 expression correlates with MDSC accumulation in cancer patients

Having demonstrated that Dkk1 directly targets $\beta$-catenin signaling in MDSCs from both mice and humans, we next wanted to determine whether increased Dkk1 expression is associated with MDSC accumulation in cancer patients. Elevated levels of Dkk1 have been observed in serum and at the primary tumor sites in pancreatic cancer. Previous studies have also shown that pancreatic cancer patients have expanded CD15 ${ }^{+}$MDSC populations (Porembka et al., 2012). We further demonstrated that MDSCs isolated from these patients have decreased $\beta$-catenin levels compared with healthy 
donors (Capietto et al., 2013), thus making this tumor model highly relevant for studying a possible correlation between Dkk1 expression and MDSC accumulation. To test our hypothesis, we obtained tissue microarrays (TMAs) from 55 T1-T3 and stage I-II tumor tissues from pancreatic cancer patients with no metastatic disease. The TMAs were blindly scored for the presence of CD $15^{+}$infiltrates and Dkk1 expression. We found tumor tissues with high Dkk1 expression both in the tumor cells and in the associated tumor stroma, and others with low Dkk1 expression (Fig. 2 I). Nevertheless, we observed that accumulation of $\mathrm{CD} 15^{+}$cells significantly correlated with increased Dkk1 expression (Spearman's $\mathrm{r}=0.27$; $\mathrm{P}<0.05$; Fig. $2 \mathrm{~J}$ ). Future studies are required to measure Dkk1 expression in the bone microenvironment and correlate this result with peripheral MDSCs. Collectively, these findings support the hypothesis that Dkk1 induces MDSC accumulation during tumor progression.

\section{Dkk1 neutralization decreases tumor growth and MDSC numbers}

To demonstrate that Dkk1 contributes to MDSC accumulation in vivo by reducing $\beta$-catenin levels in these cells, WT mice were s.c. injected with $10^{5}$ LLC, a tumor cell line which induces up-regulation of Dkk1 and increases MDSC numbers during tumor progression (Fig. 1; Capietto et al., 2013). Tumor-bearing mice were then administered anti-Dkk1 or IgG as a control $(20 \mathrm{mg} / \mathrm{kg})$ three times per week for 2 wk. Strikingly, we observed a significant decrease in tumor growth and size after anti-Dkk1 treatment compared with IgG control (Fig. 3, A and B). In support of our hypothesis, the percentages of $\mathrm{Gr}^{+} / \mathrm{CD} 11 \mathrm{~b}^{+} \mathrm{MDSC}$ in the bone marrow, spleen, and tumor were significantly reduced (Fig. $3 \mathrm{C}$ ), and $\beta$-catenin expression was rescued in MDSCs isolated from anti-Dkk1-treated mice compared with IgG controls (Fig. 3 D).

MDSCs are potent suppressors of antitumor $\mathrm{T}$ cell responses. To determine whether Dkk1 neutralization is sufficient to restore $\mathrm{T}$ cell infiltration in the tumor stroma, we measured by FACS the percentage of $\mathrm{CD}^{+}$and $\mathrm{CD}^{+} \mathrm{T}$ cells in the tumor-bearing mice treated every other day with the anti-Dkk1. Consistent with a reduction in MDSC numbers, we found that the percentages of $\mathrm{CD}^{+}$and $\mathrm{CD}^{+} \mathrm{T}$ cells were increased in anti-Dkk1-treated mice versus controls (Fig. 3 E).

MDSCs have been shown to increase with tumor burden in several models. Therefore, to ask if changes in MDSCs were caused by Dkk1 levels and not primary tumor size, we examined MDSCs in anti-Dkk1-treated and IgG control mice that were sacrificed $7 \mathrm{~d}$ after tumor injection, when no detectable differences in tumor growth were yet observed (Fig. 3 F). Confirming the similar tumor size detected by caliper measurements, the weight of the excised tumors was not different between the two groups (Fig. 3 F). Nevertheless, a significant decrease in MDSC percentage was already evident at this time point in the bone marrow, spleen, and tumor site (Fig. $3 \mathrm{G}$ ). These data indicate that the effects of
anti-Dkk1 on MDSCs precede the effects of the neutralizing antibody on tumor growth.

Because we found that Dkk1 levels were elevated in circulation and in the bone microenvironment of mice bearing B16 tumors (Fig. 1, E and G), we next asked if Dkk1 neutralization could also exert antitumor effects in this model. Indeed, anti-Dkk1 was sufficient to significantly reduce B16 subcutaneous tumor growth (Fig. $3 \mathrm{H}$ ). As with the LLC tumor model, the percentage of MDSCs was significantly reduced in the bone marrow and spleen by the anti-Dkk1 treatment (Fig. 3 I). Together, these data show that Dkk1 neutralization reduces tumor growth and MDSC accumulation during tumor progression.

\section{Dkk1 neutralization affects tumor progression in advanced cancer models}

To further exploit the therapeutic effects of anti-Dkk1 treatment, we administered anti-Dkk1 to WT mice bearing established s.c. tumors with already expanded MDSC population. 1 wk after $10^{5}$ LLC s.c. injection, animals received anti-Dkk1 or IgG control antibodies $(20 \mathrm{mg} / \mathrm{kg}$ every other day) for an additional $7 \mathrm{~d}$. We observed a significant decrease in tumor growth (Fig. 4, A and B) and concomitant reduction in MDSC percentage in the bone marrow, spleen, and tumor site of anti-Dkk1-treated mice compared with IgG controls (Fig. $4 \mathrm{C}$ ).

To determine whether Dkk1 neutralization would exert significant antitumor effects in a mouse model of pre-expanded MDSCs, we turned to PLC $\gamma 2^{-/-}$mice. We recently demonstrated that PLC $\gamma 2$-null animals have increased MDSC numbers and, in these mice, MDSCs are responsible for the higher rate of tumor growth compared with WT mice (Capietto et al., 2013). Most importantly, similarly to the cancer patients, MDSCs from PLC $\gamma 2^{-/-}$mice have significantly lower $\beta$-catenin levels than WT MDSCs (Capietto et al., 2013). Consistent with this observation, Dkk1 is significantly up-regulated in the bone microenvironment of PLC $\gamma 2^{-/-}$ tumor-bearing mice compared with controls (Fig. 4 D). To investigate whether Dkk1 neutralization would protect PLC $\gamma 2^{-/-}$mice from tumor progression by reducing MDSC numbers, $10^{5}$ LLC cells were s.c. injected into PLC $\gamma 2^{-/-}$animals after the administration of anti-Dkk1 or IgG for $14 \mathrm{~d}$. Strikingly, Dkk1 neutralization dramatically reduced tumor growth and percentage of MDSCs in the bone marrow, spleen, and tumor site compared with $\operatorname{IgG}$ controls (Fig. 4, $\mathrm{E}$ and F). Confirming that Dkk1 directly targets PLC $\gamma 2^{-/-}$ MDSCs, $\beta$-catenin levels in these cells were rescued by Dkk1 neutralization (Fig. 4 G). Importantly, the anti-Dkk1 treatment also affected MDSC functionality, as shown by a significant reduction in reactive oxygen species (ROS) and nitric oxide (NO) production in PLC $\gamma 2^{-/-}$MDSCs isolated from anti-Dkk1-treated mice compared with MDSCs from IgG controls (Fig. 4, H and I).

Together, these results indicate that anti-Dkk1 reduces established tumor growth and exerts antitumor effects in 


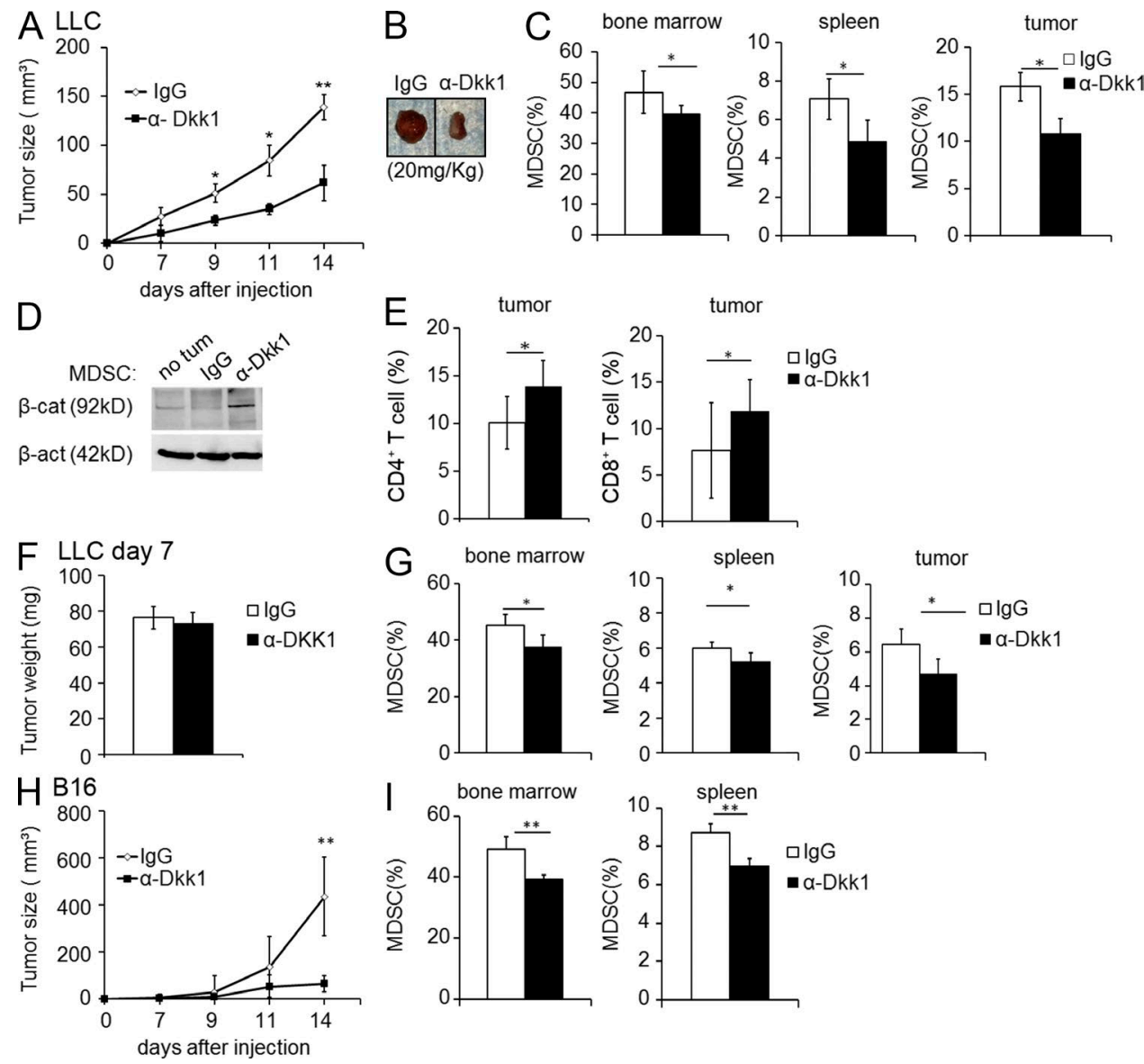

Figure 3. Dkk1 neutralization decreases tumor growth and MDSC expansion. (A) Anti-Dkk1 or lgG control antibodies (20 mg/kg, three times per week) were administered for 2 wk into WT mice s.c. injected with $10^{5}$ LLC cells. Tumor growth was evaluated by caliper measurements at indicated days. Mean \pm SD $(n=7)$ is shown. Data are reported from one of three similar independent experiments. ${ }^{*}, P<0.05 ;{ }^{* *}, P<0.01$. (B) $14 \mathrm{~d}$ after tumor injection, the tumors shown in A were resected. One representative image is shown. (C) Percentage of MDSCs in the bone marrow, spleen, and tumor was analyzed by FACS using anti-Gr1 and anti-CD11b staining. Results represent means \pm SD $(n=7)$. One representative experiment of three is shown. ${ }^{*}, P<0.05 .(D)$ MDSCs were isolated from the bone marrow of no tumor or tumor-bearing WT mice receiving IgG control or anti-Dkk1 treatment and subjected to Western blot analysis to measure $\beta$-catenin protein levels. $\beta$-Actin was used as loading control. One representative Western blot from three independent experiments is shown. (E) $C D 4^{+}$and $C D 8^{+} T$ cell percentage was analyzed by FACS in excised tumors from WT mice treated with anti-Dkk1 or lgG control. Bar graphs show mean $\pm \mathrm{SD}(n=7) .{ }^{*}, \mathrm{P}<0.05$. One representative experiment of three is shown. (F) WT mice s.c. inoculated with $10^{5}$ LLC cells were treated with anti-Dkk1 or lgG control starting 1 wk after tumor inoculation. After $7 \mathrm{~d}$ of treatment, the animals were sacrificed and the tumor was resected and weighed. Results represent mean $\pm \mathrm{SD}(n=5)$. (G) Percentage of MDSCs $\left(\mathrm{Gr} 1^{+} / \mathrm{CD} 11 \mathrm{~b}^{+}\right)$from bone marrow, spleen, and tumor of mice in F were then analyzed by FACS staining. Results represent mean \pm SD $(n=5)$. ${ }^{*}, P<0.05$. (H) Tumor growth in mice inoculated with $10^{5}$ B16 cells treated with IgG or anti-Dkk1 was evaluated by caliper measurements for the indicated days. Mean \pm SD $(n=5)$ is shown. Data reported from one of three similar independent experiments. **, $\mathrm{P}<0.01$. (I) Percentage of $\mathrm{Gr} 1^{+} / \mathrm{CD} 11 \mathrm{~b}^{+} \mathrm{MDSC}$ from bone marrow and spleen of mice treated as in $\mathrm{H}$ were analyzed by FACS staining. Results represent mean $\pm \mathrm{SD}(n=5) .{ }^{*}, \mathrm{P}<0.01$.

mouse models of preexpanded MDSCs by decreasing MDSC numbers and functionality.

\section{MDSCs are a direct target of anti-Dkk1 treatment}

To determine whether Dkk1 neutralization reduces tumor growth by increasing $\beta$-catenin levels in MDSCs, and not by targeting other cell populations, we analyzed the effects of anti-Dkk1 treatment in $\beta$-catenin-floxed mice expressing the Cre recombinase under the control of Lysozyme M (LysM-Cre/ $\beta$-catenin ${ }^{\text {flox} / \text { llox }}$; herein defined as $\beta$ catcKo). We previously demonstrated that MDSCs from $\beta$ catcKo mice do not express $\beta$-catenin (Capietto et al., 2013). LLC cells were injected s.c. into $\beta$ catcKo animals, followed by anti-Dkk1 or IgG treatment, three times a week for 2 wk. Tumor growth was followed by caliper measurements at indicated days and the tumor mass was resected and weighed. In contrast to WT mice, anti-Dkk1 treatment did not affect the growth or size of the LLC tumors (Fig. 5 A, B); more importantly, Dkk1 neutralization did not reduce the percentage of MDSCs in the bone marrow, spleen, or tumor site of $\beta$ catcKo ani- 

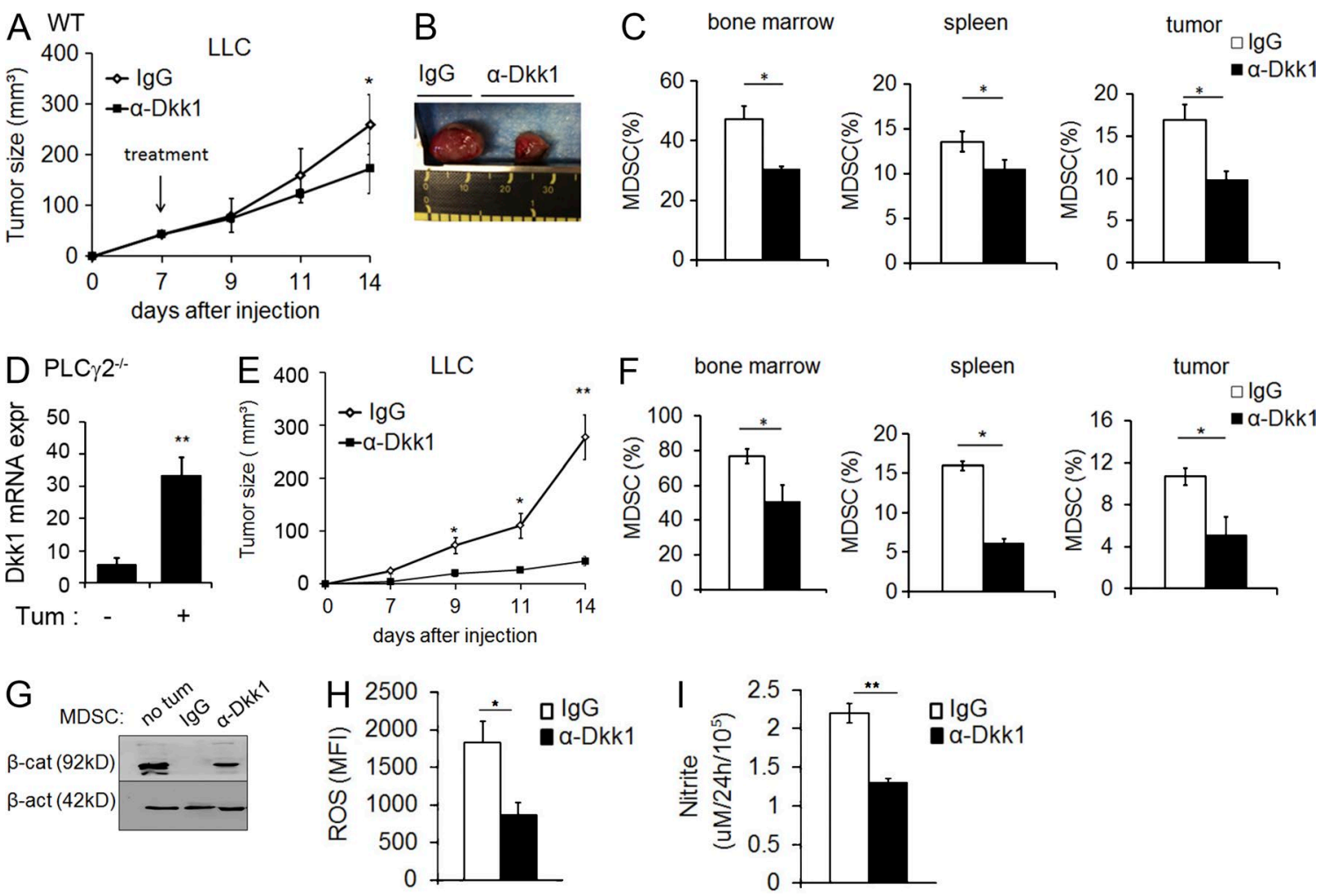

Figure 4. Dkk1 neutralization reduces tumor progression in tumor models of preexpanded MDSCs. (A and B) $10^{5}$ LLC cells were S.c. injected in WT mice and anti-Dkk1 and IgG treatments $(20 \mathrm{mg} / \mathrm{ml})$ were administered $7 \mathrm{~d}$ after tumor inoculation and treated for seven additional days. Tumor growth was assessed by caliper measurements. Mean $\pm \mathrm{SD}(n=5)$ is shown. ${ }^{*}, \mathrm{P}<0.05$. (B) Representative image of tumors as shown in $\mathrm{A}$. (C) Percentage of $\mathrm{Gr} 1^{+} /$ CD $11 b^{+}$MDSCs isolated from bone marrow, spleen, and tumor of mice treated as in A was determined by FACS. Results represent means \pm SD $(n=5) .{ }^{*}, P<$ 0.05. (D) Dkk1 mRNA expression in crushed bones devoid of bone marrow cells of PLC $\gamma 2^{-1-}$ mice s.c. injected with $10^{5} \mathrm{LLC}$ cells. Mean $\pm \mathrm{SD}(n=5)$ is shown. ${ }^{* *}, \mathrm{P}<0.01$. (E) Tumor growth in PLC $\gamma 2^{-1-}$ mice injected s.c. with $10^{5} \mathrm{LLC}$ cells and treated with anti-Dkk1 or lgG control $(20 \mathrm{mg} / \mathrm{kg})$ three times per week for 2 wk starting at time of LLC injection. Tumor size was determined by caliper measurements. $n=4$, representative of three independent experiments. ${ }^{*}$, $P$ $<0.05 ;{ }^{* *}, \mathrm{P}<0.01$. (F) Percentage of $\mathrm{Gr}^{+} / \mathrm{CD} 11 \mathrm{~b}^{+} \mathrm{MDSC}$ isolated from bone marrow, spleen, and tumor of mice treated as in $\mathrm{E}$ was determined by FACS. Mean \pm SD. $n=4$; representative of three independent experiments. ${ }^{*}, \mathrm{P}<0.05$. (G) $\beta$-Catenin protein levels were measured by Western blot in PLC $\gamma 2^{-l-}$ MDSCs isolated from the bone marrow of no tumor or tumor-bearing mice after lgG and anti-Dkk1 treatment. $\beta$-Actin was used as loading control. One representative Western blot is shown. ( $\mathrm{H}$ and I) ROS and NO levels measured in PLC $\gamma 2^{-1-}$ MDSCs isolated from tumor-bearing mice treated with anti-Dkk1 or $\lg \mathrm{G}$ as control. Data are reported from one of two independent experiments. Mean from biological triplicates $\pm \mathrm{SD} .{ }^{*}, \mathrm{P}<0.05 ;{ }^{* *}, \mathrm{P}<0.01$.

mals (Fig. 5 C). Consistent with our previous observation showing that the expression of a constitutively active form of $\beta$-catenin in myeloid cells limits tumor growth by reducing MDSC numbers and functionality (Capietto et al., 2013), we now demonstrate that Dkk1 neutralization exerts profound antitumor effects by restoring $\beta$-catenin levels in the myeloid compartment.

To further establish that the Dkk1-neutralizing antibody targets MDSCs, and not other immune cell populations, we injected $10^{5}$ LLC into WT mice receiving anti-Gr1 (12.5 $\mathrm{mg} / \mathrm{kg}$ ) to deplete MDSCs in the presence or in the absence of anti-Dkk1. Mice receiving IgG were used as controls. As shown previously, anti-Gr1 exerts significant antitumor effects (Mundy-Bosse et al., 2011). The reduction in tumor growth after anti-Gr1 treatment was similar to that observed in mice treated with anti-Dkk1 (Fig. 5 D). No further decrease in tumor growth was noted in mice receiving both
anti-Gr1 and anti-Dkk1 compared with each treatment alone (Fig. 5 D). Consistent with our hypothesis that anti-Dkk1 targets MDSCs, Dkk1 neutralization induced a similar reduction in the percentage of MDSCs at tumor site to that observed in mice treated with anti-Gr1 alone or anti-Gr1 plus anti-Dkk1 (Fig. 5 E). These results demonstrate that the antitumor effects of Dkk1 neutralization overlap with those of the anti-Gr1, further implicating Dkk1 as an important regulator of tumor-induced MDSCs.

\section{Dkk1 controls MDSC immune suppressive effects}

Because one of the best-characterized functions of MDSCs is to actively suppress cytotoxic $\mathrm{T}$ cell responses, we examined whether $\mathrm{T}$ cells were important players in mediating the antitumor effects of the anti-Dkk1. To this end, we injected $10^{5}$ LLC cells s.c. into Nude mice, which lack T cell populations, and administered anti-Dkk1 or $\operatorname{IgG}$ antibodies as described in 

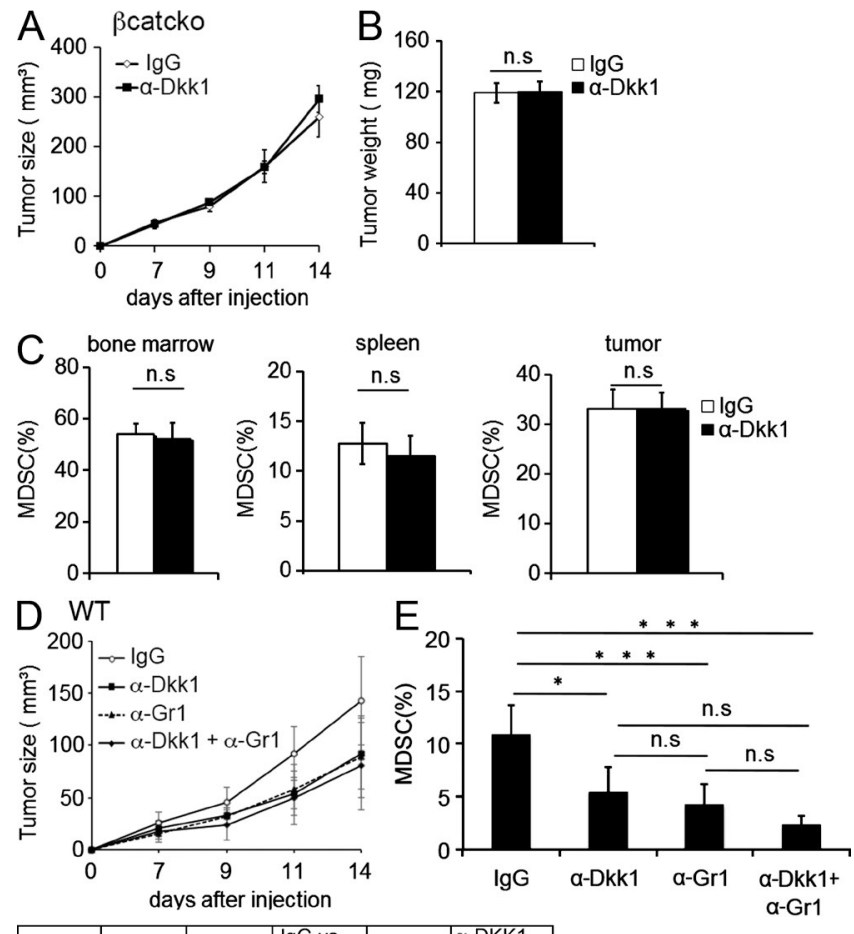

\begin{tabular}{|l|c|c|c|c|c|}
\hline P values & $\begin{array}{l}\text { IgG vs } \\
\alpha-D K K 1\end{array}$ & $\begin{array}{l}\text { IgG vs } \\
\alpha-G r 1\end{array}$ & $\begin{array}{l}\text { IgG vs } \\
\alpha-D K K 1 \\
+\alpha-G r 1\end{array}$ & $\begin{array}{c}\alpha-G r 1 \text { vs } \\
\alpha-D K K 1\end{array}$ & $\begin{array}{c}\alpha-D K K 1 \\
+\alpha-G r 1 \\
\alpha-D K K 1\end{array}$ \\
\hline Day 7 & n.s & n.s & n.s & n.s & n.s \\
\hline Day 9 & n.s & n.s & n.s & n.s & n.s \\
\hline Day 11 & ${ }^{* * p<0.01}$ & ${ }^{*} p<0.05$ & ${ }^{* *} p<0.01$ & n.s & n.s \\
\hline Day 14 & ${ }^{* * p<0.001}$ & ${ }^{* *} p<0.001$ & ${ }^{* *} p<0.001$ & n.s & n.s \\
\hline
\end{tabular}

Figure 5. Dkk1 neutralization loses its antitumor effects in $\beta$ catcko mice and after MDSC depletion. ( $A$ and B) $10^{5} \mathrm{LLC}$ cells were s.c. injected in $\beta$ catcKo mice and anti-Dkk1 or lgG as control $(20 \mathrm{mg} / \mathrm{kg})$ were administered three times per week. Tumor growth was followed by caliper measurements (A) and, 2 wk later, tumors were resected and weighed (B). Mean $\pm \mathrm{SD}(n=8)$. Data are reported from one of two independent experiments. n.s., not significant. (C) Percentage of $\mathrm{Gr}^{+} / \mathrm{CD} 11 \mathrm{~b}^{+} \mathrm{MDSC}$ s isolated from bone marrow, spleen, and tumor of mice in A was determined by FACS. Results represent means $\pm \mathrm{SD}(n=8)$. One representative experiment of two is shown. n.s., not significant. (D) $10^{5} \mathrm{LLC}$ cells were s.c. injected in WT mice, and $\mathrm{lgG}$, anti-Dkk1 (20 mg/kg), anti-Gr1 (12.5 mg/kg), or anti-Dkk1 plus anti-Gr1 were administered three times per week. Tumor growth was followed by caliper measurements. Mean \pm SD ( $n=6 / 7$ mice group). P-values are shown in table. (E) Percentage of $\mathrm{Gr} 1^{+} / \mathrm{CD} 11 \mathrm{~b}^{+}$MDSCs in tumors from mice treated as in $D$ was determined by FACS. Results represent means \pm $\mathrm{SD}(n=6 / 7) .{ }^{*}, \mathrm{P}<0.05 ;{ }^{* * *}, \mathrm{P}<0.001$. n.S., not significant.

the Materials and methods. We found no differences in tumor growth between anti-Dkk1 and $\operatorname{IgG}$ control-treated mice at late stages of tumor progression (Fig. $6 \mathrm{~A}$ ). This finding indicates that $\mathrm{T}$ cells are required for anti-Dkk1 long-term antitumor effects, leading to the hypothesis that Dkk1 targeting may reduce MDSC immune suppressive functions.

ROS production is one of the mechanisms attributed to MDSC ability to suppress T cell responses. To determine whether Dkk1 directly affects MDSC functionality, we measured ROS levels in MDSCs isolated from WT mice and stimulated in vitro with $\mathrm{rDkk} 1(1 \mu \mathrm{g} / \mathrm{ml})$. Consistent with our hypothesis, rDkk1 significantly increased ROS production by MDSCs (Fig. 6 B).

Next, to test whether anti-Dkk1 treatment impacts MDSC functionality, we examined the ability of MDSCs isolated from tumor-bearing mice treated with anti-Dkk1 or IgG to suppress $\mathrm{T}$ cell proliferation ex vivo. CSFE-labeled splenocytes from naive WT mice were incubated with anti-CD3 $(10 \mu \mathrm{g} / \mathrm{ml})$ to induce mitogen-driven $\mathrm{CD}^{+} \mathrm{T}$ cell proliferation in the presence of MDSCs isolated from tumorbearing mice treated with anti-Dkk1 or IgG control. Three different ratios of MDSCs/splenocytes (1:10, 1:5, and 1:1) were tested and proliferation of targeted $\mathrm{CD}^{+} \mathrm{T}$ cells was measured in terms of CFSE dilution by FACS analysis $72 \mathrm{~h}$ later. MDSCs isolated from anti-Dkk1-treated WT mice displayed reduced $\mathrm{T}$ cell immune suppressive effects compared with MDSCs from IgG controls (Fig. 6 C). Consistent with the in vitro observations, increased percentage of $\mathrm{T}$ cells in the spleen and primary tumor was also observed in vivo in tumor-bearing WT mice after treatment with anti-Dkk1 (Fig. $6 \mathrm{D}$ and $3 \mathrm{E}$ ). To further evaluate whether the number of activated $\mathrm{T}$ cells is also increased upon treatment with antiDkk1, we measured the percentage of activated CD44 ${ }^{\text {hi }}$ CD62 $\mathrm{L}^{\text {low }}$ and memory CD44 ${ }^{\text {hi }} \mathrm{CD} 62 \mathrm{~L}^{\text {hi }}$, splenic $\mathrm{CD} 4^{+}$and $\mathrm{CD}^{+} \mathrm{T}$ cells in WT mice $14 \mathrm{~d}$ after tumor injection. Our data show higher percentage of activated and memory $\mathrm{T}$ cells in mice treated with anti-Dkk1 (Fig. 6, E and F).

As previously shown, PLC $\gamma 2^{--}$MDSCs have very strong immunosuppressive effects (Capietto et al., 2013). Treatment with anti-Dkk1 significantly reduced PLC $\gamma 2^{-/-}$ MDSC ability to suppress $\mathrm{T}$ cell proliferation ex vivo (Fig. $6 \mathrm{G}$ ), and increased $\mathrm{CD}^{+}$and $\mathrm{CD} 8^{+} \mathrm{T}$ cell percentages in the spleen of PLC $\gamma 2^{-/-}$tumor-bearing mice in vivo (Fig. $6 \mathrm{H}$ ). These results are consistent with reduced ROS and NO levels observed in PLC $\gamma 2^{-/-}$MDSCs isolated from anti-Dkk1-treated mice (Fig. 4 H, I).

In contrast, Dkk1 neutralization did not affect the immunosuppressive capacities of $\beta$ catcKo MDSCs, as shown by a similar T cell proliferation rate by $\beta$ catcKo MDSCs isolated from IgG and anti-Dkk1-treated mice (Fig. 6 I). In agreement with the in vitro findings, anti-Dkk1 treatment failed to increase the $\mathrm{T}$ cell percentage in the spleen of tumorbearing $\beta$ catcKo (Fig. $6 \mathrm{~J}$ ).

Collectively, these results indicate that Dkk1 exerts immune suppressive effects by targeting $\beta$-catenin levels in MDSCs, thus controlling MDSC accumulation and their ability to suppress $\mathrm{T}$ cell activation and proliferation.

\section{DISCUSSION}

This study demonstrates that Dkk1, an antagonist of the Wnt- $\beta$-catenin pathway, supports tumor progression by creating an immune suppressive environment where tumor cells can grow unabated. We show that Dkk1 neutralization confers protection from tumor growth by reducing the generation and the $\mathrm{T}$ cell suppressive effects of MDSCs. To our 

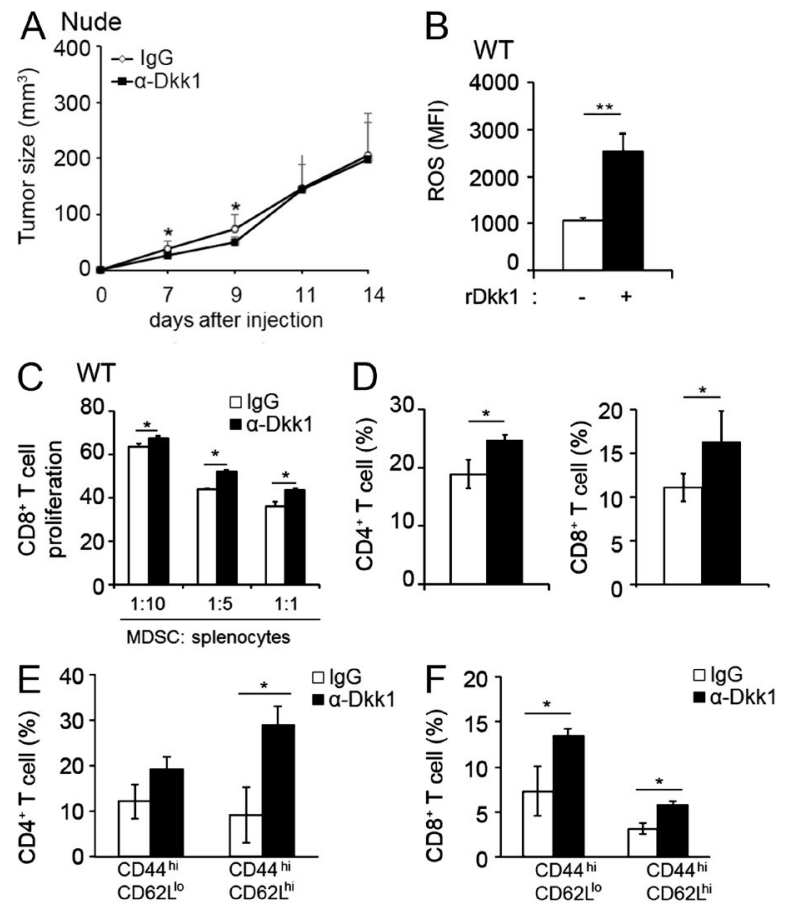

G PLC $2^{-1-}$
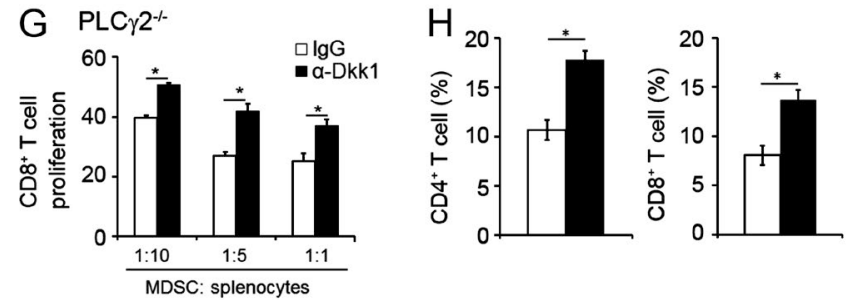

I BcatcKo
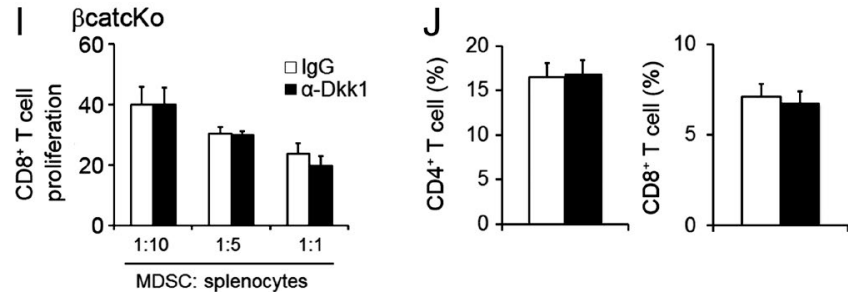

Figure 6. Neutralization of Dkk1 decreases MDSC immune suppressive activity. (A) $10^{5} \mathrm{LLC}$ cells were s.c. injected in Nude mice and anti-Dkk1 or $\lg G$ as control $(20 \mathrm{mg} / \mathrm{kg})$ were administered three times per week. Tumor growth was followed by caliper measurements. Mean \pm SD $(n=8)$. ${ }^{*}, \mathrm{P}<0.05$. (B) ROS production in $\mathrm{Gr}^{+} / \mathrm{CD} 11 \mathrm{~b}^{+}$cells from naive WT mice and stimulated in vitro with rDkk1 for $24 \mathrm{~h}$. Bar graphs show mean \pm SD of biological triplicates. Representative of two independent experiments. ${ }^{*}, P<0.01$. (C) MDSCs, isolated from WT tumor-bearing mice treated with anti-Dkk1 or lgG, were co-cultured for $3 \mathrm{~d}$ with CFSE-labeled splenocytes from naive mice in the presence of anti-CD3 $(10 \mu \mathrm{g} / \mathrm{ml})$. CD8 ${ }^{+} \mathrm{T}$ cell proliferation was measured in terms of CFSE dilution. Bar graphs show mean $\pm S D$ of three independent experiments. ${ }^{*}, P<0.05$. (D) Percentage of $\mathrm{CD}^{+}$and $\mathrm{CD} 8^{+} \mathrm{T}$ cells isolated from the spleen of WT tumor-bearing mice treated with anti-Dkk1 or $\lg G$ as control was analyzed by FACS. Bar graphs show mean $\pm \mathrm{SD}$. $n=7$. ${ }^{*}, \mathrm{P}<0.05$. (E and F) Percentage of $\mathrm{CD} 44^{\text {high }} \mathrm{CD} 2 \mathrm{~L}^{\text {low }}$ or $\mathrm{CD} 44^{\text {high }} \mathrm{CD} 2 \mathrm{~L}^{\text {high }} \mathrm{CD}^{+}$and $\mathrm{CD} 8^{+} \mathrm{T}$ cells in spleen of WT tumor-bearing mice after anti-Dkk1 and IgG treatment was measured by FACS. Bar graphs show mean $\pm \mathrm{SD}(n=7)$. ${ }^{*}, \mathrm{P}<0.05$. (G) $\mathrm{CD} 8^{+} \mathrm{T}$ cell knowledge, this is the first study demonstrating that MDSCs are a direct target of $\mathrm{Dkk} 1$, thus providing new insights as to why elevated circulating levels of Dkk1 correlate with poor prognosis in cancer patients.

In bone, Dkk1 negatively regulates osteoblast differentiation and enhances osteoclast formation, and therapies aimed at targeting Dkk1 are in consideration for post-menopausal osteoporosis (Zhang and Drake, 2012). High levels of Dkk1 are also observed in various cancer patients without detectable metastases to bone (Yamabuki et al., 2007; Liu et al., 2014). However, the mechanism by which Dkk1 exerts its protumorigenic effects has not been elucidated. Studies in MM indicate that Dkk1 changes the bone microenvironment by creating a hospitable niche that allows dissemination and proliferation of tumor cells (Fowler et al., 2012). Interestingly, although administration of anti-Dkk1 reduces tumor burden in vivo, the growth of MM cells is not affected in vitro, suggesting that the bone microenvironment is the target of the anti-Dkk1 treatment rather than the MM tumor cells (Yaccoby et al., 2007). In support of this assumption, Dkk1 is found to be highly expressed by bone marrow stromal cells and knockdown of Dkk1 in these cells decreases myeloma progression in mice (Fowler et al., 2012). These studies support a model in which Dkk1 produced by bone marrow stromal cells induces the activation of bone resorbing osteoclasts and the release of tumor-promoting factors stored in the bone matrix that favor MM growth. However, although it is certainly possible that osteoclasts mediate Dkk1 protumor effects through the release of latent factors present in the bone matrix, this model does not explain why elevated Dkk1 levels correlate with poor prognosis in cancer patients with no detectable tumors in bone. Regulation of extraskeletal tumors by resorbing osteoclasts needs to be further investigated. Pharmaceutical activation of bone resorbing osteoclasts enhances breast cancer growth in bone, but not outside the bone (Yang et al., 2013). Similarly, RANKL, a potent stimulator of osteoclastogenesis, increases prostate cancer cell growth in bone but not in soft tissues (Zheng et al., 2014). These data suggest that the Dkk1's protumor effects may not be solely related to its ability to enhance osteoclast activities.

Our work demonstrates a previously unidentified immune modulatory role for Dkk1 as a key player in the accumulation and activation of immunosuppressive myeloid cells. By

proliferation assay was performed as in C using WT splenocytes co-cultured with PLC $\gamma 2^{-1-}$ MDSCs. Bar graphs show mean \pm SD of three independent experiments. ${ }^{*}, \mathrm{P}<0.05$. $(\mathrm{H})$ Percentage of $\mathrm{CD} 4^{+}$and $\mathrm{CD} 8^{+} \mathrm{T}$ cells in spleen of $\mathrm{PLC} \gamma 2^{-l-}$ tumor-bearing mice after anti-Dkk1 or lg $\mathrm{G}$ treatment was measured by FACS. Bar graphs show mean \pm SD $(n=3$, representative of three independent experiments). ${ }^{*}, \mathrm{P}<0.05$. (I) $\mathrm{CD} 8^{+} \mathrm{T}$ cell proliferation assay as in $C$ in the presence of $\beta$ catcKo MDSCs isolated from anti-Dkk1 and $\lg G$ antibody-treated mice. Bar graphs show mean \pm SD. $n=3$. (J) Percentage of $\mathrm{CD}^{+}$and $\mathrm{CD} 8^{+} \mathrm{T}$ cells in spleen of $\beta$ catcKo tumor-bearing mice after anti-Dkk1Ab and IgG treatment was measured by FACS. Bar graphs show mean $\pm \mathrm{SD}(n=8)$, representative of two independent experiments. 
using extraskeletal tumor models consisting of mice injected subcutaneously with LLC or B16 tumor lines, we report that neutralization of Dkk1 reduces tumor growth, limits MDSC expansion, decreases MDSC immune suppressive effects and, in turn, increases $\mathrm{T}$ cell numbers and activation in the spleen and primary tumor. Importantly, we further demonstrate that Dkk1 neutralization reduces growth of established tumors and also exerts potent antitumor effects in mice lacking PLC $\gamma 2$, which have increased numbers of MDSCs.

Decreased PLC $\gamma 2$ and $\beta$-catenin levels have been previously observed in patients with advanced cancer $(\mathrm{Ca}-$ pietto et al., 2013). Mice lacking PLC $\gamma 2$ have expanded MDSC numbers with very low $\beta$-catenin expression, and tumor growth is increased compared with WT animals. As a consequence of the significant MDSC accumulation and activation, PLC $\gamma 2^{-/-}$mice have impaired antitumor $\mathrm{T}$ cell responses; however, adoptive $\mathrm{T}$ cell transfer has only limited antitumor effects in these animals (Zhang et al., 2011), suggesting that MDSCs establish a very strong immune suppressive environment in these animals. We now demonstrate that neutralization of Dkk1 exerts significant antitumor effects in PLC $\gamma 2^{-/-}$mice by reducing MDSC accumulation and functionality and consequently increasing the percentage of $\mathrm{T}$ cells. This finding, in conjunction with the protective effect of anti-Dkk1 treatment on established tumors, suggests that an anti-Dkk1 could potentially be a useful antitumor therapy for advanced cancer patients. Previous studies have shown expanded $\mathrm{CD}^{+} 5^{+}$MDSC population (Porembka et al., 2012) with reduced $\beta$-catenin levels (Capietto et al., 2013) in pancreatic cancer. We now find a correlation between Dkk1 levels and tumor-infiltrating $\mathrm{CD} 15^{+}$cells in these patients. Further studies, however, are needed to determine whether bonederived Dkk1 might have a stronger correlation with MDSC numbers and if Dkk1 induces $\mathrm{CD}^{+} 5^{+}$cell accumulation in other types of cancer, where Dkk1 levels are low at tumor site.

The finding that an anti-Dkk1 suppresses growth of tumors residing outside the bone is an important observation. $\beta$-catenin is a known regulator of tumor cell proliferation. Systemic administration of anti-Dkk1 in tumorbearing mice could, therefore, also target the tumor cells and enhance their proliferation by increasing $\beta$-catenin expression. Although certainly possible for some tumors more strictly dependent on $\beta$-catenin levels for their growth, our data demonstrate that restoring the expression of $\beta$-catenin in myeloid cells and, more specifically, in MDSCs, is sufficient to exert potent antitumor effects. These findings are in agreement with the tumor phenotype of mice expressing a nondegradable form of $\beta$-catenin in myeloid cells, which are protected from tumor growth as a result of limited MDSC expansion (Capietto et al., 2013). Similarly, we now show that Dkk1 neutralization increases $\beta$-catenin expression in MDSCs and limits their ability to suppress $\mathrm{T}$ cell proliferation. Importantly, the antitumor effects of the neutralizing antibody are lost in mice lacking $\beta$-catenin in myeloid cells. These data demonstrate that the antitumor ef- fects of systemic anti-Dkk1 administration are mediated by the myeloid compartment.

We propose that MDSCs are the primary target of Dkk1. MDSCs express LRP5/6 co-receptors. Induction of LRP5 and LRP6 transcripts is also observed in naive bone marrowderived $\mathrm{Gr}^{+} / \mathrm{CD} 11 \mathrm{~b}^{+}$cells cultured in vitro in the presence of $10 \%$ serum from tumor-bearing mice. Most importantly, these cells respond to $\mathrm{rDkk} 1$ with reduced $\beta$-catenin protein levels and $\beta$-catenin target gene expression. Although we don't currently know whether additional factors present in the serum from the tumor-bearing mice are required to support a more robust response to $\mathrm{rDkk} 1$ in vitro, most likely increased expression of the Dkk1 target receptors LRP5 and LRP6 mediates these effects. Similar to the mouse model, rDkk1 also directly targets human MDSCs by decreasing mRNA expression levels of $\beta$-catenin target genes, which are restored upon depletion of Dkk1 from the serum of cancer patients. Furthermore, we also show that Dkk1 neutralization does not exert additional antitumor effects in mice treated with an anti-Gr1 to deplete MDSCs, suggesting that the two antibodies target the same myeloid population. Notably, antiDkk1 and anti-Gr1 treatments induce a similar reduction in tumor growth and MDSC numbers.

Whereas MDSCs are certainly a direct target of Dkk1, we also observe that anti-Dkk1 antitumor effects depend on $\mathrm{T}$ cells. Indeed, Dkk1 neutralization fails to reduce tumor growth in Nude mice that lack $\mathrm{T}$ cells. This result, together with the loss of antitumor effects in $\beta$ catcKo mice, suggests that anti-Dkk1 protects from tumor growth by reducing MDSC numbers at tumor site, and consequently restoring $\mathrm{T}$ cell recruitment/activation. In support of this hypothesis, the percentage of activated and memory $\mathrm{T}$ cells in animals treated with an anti-Dkk1 was increased compared with IgG controls.

Very little is known about the regulation of Dkk1 during tumor progression. Here, we report that LLC and B16 tumor cell lines do not express Dkk1 in vitro. However, Dkk1 levels are significantly increased in circulation in LLC and B16 tumor-bearing mice. Although we can detect Dkk1 expression at tumor site, Dkk1 mRNA levels in the bone are 500-fold higher than in the tumor mass. This finding is further supported by the elevated Dkk1 protein levels measured in the bone microenvironment of tumor-bearing mice versus no tumor controls. This observation is very important because it supports a prominent role for bone-derived Dkk1 and indicates that it exerts profound protumor effects, even when tumors are located outside the bone. Human studies have measured circulating Dkk1 levels, with several showing increased Dkk1 expression in circulation and in the primary tumors (Yamabuki et al., 2007; Liu et al., 2014). Bone expression of Dkk1 in cancer patients with no detectable tumors in bone has never been evaluated. Future studies will have to determine whether bone-derived Dkk1 correlates with immune suppression in cancer patients and what are the paracrine factors that regulate Dkk1 expression in bone when the tumor resides outside the bone. 
In conclusion, our study demonstrates that Dkk1 is a negative modulator of antitumor immune responses via targeting myeloid suppressor cells in both mice and humans. We propose a model whereby an incipient tumor induces the expression of Dkk1 by bone-resident cells and, to a lesser extent, in the primary tumor. Importantly, Dkk1 production by the bone microenvironment drives MDSC accumulation during tumor progression while Dkk1 expression by the tumor stroma might control MDSC recruitment and immune suppressive functions at tumor site.

\section{MATERIALS AND METHODS}

Animals and tumor models. Animals were housed in a pathogen-free animal facility at Washington University (St. Louis, MO). 6-8-wk-old littermate mice were used in all experiments according to protocols approved by the Institutional Animal Care and Use Committee chaired by D.R. Abendschein. WT, PLC $\gamma 2^{-/-}$, and LysM-Cre/ $\beta$-catenin ${ }^{\text {flox/flox }}$ ( $\beta$ catcKo) mice were on $\mathrm{C} 57 \mathrm{BL} / 6$ background and were previously described (Capietto et al., 2013). Nude mice were purchased from The Jackson Laboratory. All in vivo figures are shown as representative experiments.

LLC (C57BL/6 mouse LLC) and B16 (C57BL/6 mouse melanoma cells) were cultured at $37^{\circ} \mathrm{C}$ in complete media (DMEM supplemented with $2 \mathrm{mM}$ L-glutamine, 100 $\mu \mathrm{g} / \mathrm{ml}$ streptomycin, $100 \mathrm{IU} / \mathrm{ml}$ penicillin, and $1 \mathrm{mM}$ sodium pyruvate) containing $10 \%$ FBS. To establish tumors, B16 $\left(10^{5}\right)$ and LLC $\left(10^{5}\right)$ tumor cells were suspended in PBS and inoculated s.c. in the flank of sex- and age-matched mice. Tumor measurements were performed every 2 or $3 \mathrm{~d}$ with a caliper and volumes were calculated using the following formula: $\mathrm{V}=1 / 2\left(\right.$ length $[\mathrm{mm}] \times$ width $\left.[\mathrm{mm}]^{2}\right)$.

Antibody neutralization. Anti-Dkk1 neutralizing antibody and IgG isotype control were provided by Amgen. Treatment consisted of s.c. injections in the flank of mice of anti-Dkk1 and $\mathrm{IgG}$ control at dose of $20 \mathrm{mg} / \mathrm{kg}$ three times a week for $14 \mathrm{~d}$. Anti-Gr1Ab was purchased from Bio X Cell and injected i.p. at a concentration of $12.5 \mathrm{mg} / \mathrm{kg}$ three times a week for 2 wk. Recombinant mouse Dkk1 protein was purchased from R\&D Systems and used at the concentration of $100 \mathrm{ng} / \mathrm{ml}$ for qRT-PCR analysis of $\beta$-catenin target genes or $1 \mu \mathrm{g} / \mathrm{ml}$ for ROS production.

Mouse Dkk1 ELISA assay. Dkk1 levels from serum and bone marrow interstitial fluid of B16 and LLC tumor-bearing mice or tumor-free animals were measured by ELISA according to the manufacturer's instructions (R\&D Systems). In brief, for measurements of Dkk1 in the bone marrow interstitial fluid, tibias and femurs were collected and placed in a plate with PBS until all bones were collected. The tibia and femur from each leg were then spun in microcentrifuge tubes with the tip cut off and placed inside a larger microcentrifuge tube to collect the bone marrow. The bone marrow was suspended in $40 \mu \mathrm{l}$ of PBS and centrifuged at 8,000 RPM for 5 min to separate the marrow cells from the supernatant, and then $10 \mu \mathrm{l}$ of supernatant from each set of legs were used for the ELISA assay. Final concentration of Dkk1 in the bone marrow interstitial fluid was calculated by taking into consideration the volume of PBS used to dilute the bone marrow from each set of legs.

Flow cytometric analysis. Immediately upon sacrifice, singlecell suspensions were prepared from bone marrow, spleen, and tumor. In brief, bone marrow cells were harvested from tibias and femurs by centrifugation, whereas spleens were mechanically dissociated and individual cell suspensions were obtained through a 70- $\mu \mathrm{m}$ cell strainer. Tumor tissues were minced, and then digested with $3.0 \mathrm{mg} / \mathrm{ml}$ collagenase A (Roche) and $50 \mathrm{U} / \mathrm{ml}$ DNase I (Sigma-Aldrich) in serum free media for $30 \mathrm{~min}$ at $37^{\circ} \mathrm{C}$. Cells were filtered through 40- $\mu \mathrm{m}$ nylon strainers (Thermo Fisher Scientific), and washed twice in PBS with 2\% FBS. Red blood cells were then removed with red blood cell lysis buffer (Sigma-Aldrich). Cells were washed once and stained in PBS with $0.5 \%$ FBS with the following anti-mouse antibodies: allophycocyanin (APC)conjugated $\alpha-\mathrm{Gr} 1 \mathrm{Ab}$ and eFluor450-conjugated anti-CD44 (eBioscience), phycoerythrin (PE)-conjugated antibody to CD11b, APC-conjugated anti-CD $8 \alpha$, and FITC-conjugated anti-CD4 (BD), Brilliant Violet 605 anti-CD62L (BioLegend). The respective isotype-matched conjugated controls were purchased from eBioscience and BD, respectively. Corresponding isotope controls yielded no significant staining. Acquisition was performed on a FACSCalibur and the dedicated software CellQuest (BD). Data were analyzed with FlowJo 7.5.5 software (Tree Star).

MDSC isolation. MDSCs were isolated from bone marrow using the Myeloid-Derived Suppressor Cell Isolation kit (Miltenyi Biotec), and $>95 \%$ cell purity was confirmed by flow cytometric analysis using anti-CD11b and anti-Gr1. When indicated, $\mathrm{Gr}^{+} / \mathrm{CD} 11 \mathrm{~b}^{+}$cells were isolated from naive mice and cultured in vitro in medium supplemented with 10\% serum from tumor-bearing mice, $10 \mathrm{ng} / \mathrm{ml}$ GMCSF, and $40 \mathrm{ng} / \mathrm{ml}$ IL-6.

Human PBMCs from healthy donors were obtained at Washington University. In brief, informed consent was prospectively obtained from all the blood donors according to an institutionally approved Human Studies Committee Protocol. Peripheral blood samples were collected in vacuum tubes containing EDTA (BD). PBMCs were isolated by Ficolldensity centrifugation and frozen in DMSO with 10\% FBS. For the experiment, thawed cells were washed and prepared for cell isolation using CD33 microbeads with MiniMACS columns according to the manufacturer's protocol (Miltenyi Biotec). Purity was confirmed by flow cytometry (>95\%). RNA isolation was immediately performed.

ROS and NO production. For ex vivo ROS production, MDSCs were isolated from LLC tumor-bearing mice treated 
with anti-Dkk1 neutralizing antibody or IgG control for 14 d. $10^{5}$ cells were then incubated for $30 \mathrm{~min}$ in the presence of oxidation-sensitive dye DCFDA $(3 \mu \mathrm{M})$. MDSCs were stained with anti-Gr1 and CD11b antibodies and ROS production in the cells was evaluated FACS analysis.

For in vitro ROS production, $10^{5} \mathrm{Gr}^{+} / \mathrm{CD} 11 \mathrm{~b}^{+}$cells were isolated from naive mice and cultured in RPMI 1640 supplemented with $10 \mathrm{ng} / \mathrm{ml} \mathrm{GMCSF}+40 \mathrm{ng} / \mathrm{ml} \mathrm{IL-6}$, and then stimulated with $1 \mu \mathrm{g} / \mathrm{ml} \mathrm{rDkk} 1$ for $24 \mathrm{~h}$ in the presence of PMA (300 nM; Sigma-Aldrich) for the last $30 \mathrm{~min}$. ROS detection by FACS was performed as described above.

For NO levels, $10^{5} \mathrm{MDSC}$ isolated from tumor-bearing mice receiving anti-Dkk1 or IgG antibodies were cultured in RPMI 1640 media supplemented with $10 \mathrm{ng} / \mathrm{ml} \mathrm{GM-CSF}+$ $40 \mathrm{ng} / \mathrm{ml}$ IL-6 and stimulated with $1 \mu \mathrm{g} / \mathrm{ml}$ LPS for $24 \mathrm{~h}$. $100 \mu \mathrm{l}$ of culture supernatants were incubated for $10 \mathrm{~min}$ at room temperature with Greiss reagent (1\% sulfanilamide, $0.1 \% \mathrm{~N}$-[1-naphthyl] ethyl-enediamine, and $\left.5 \% \mathrm{H}_{3} \mathrm{PO}_{4}\right)$ to measure the nitrite concentrations. The absorbance at $540 \mathrm{~nm}$ was measured using a microplate reader (Bio-Tek). Nitrite concentrations were determined by comparing the absorbance values from the samples to a standard curve generated by serial dilutions of sodium nitrite $(0.25 \mathrm{mM})$.

T cell suppression assay. Freshly isolated splenocytes $\left(5 \times 10^{6}\right.$ cells/ml) from WT mice were depleted of red cells with Red Blood Cells Lysis Buffer (Sigma-Aldrich) and labeled with CFSE (1 $\mu \mathrm{M}$; Molecular Probes) for $10 \mathrm{~min}$ at $37^{\circ} \mathrm{C}$ and washed with fresh culture media. Splenocytes were stimulated with anti-CD3 $(10 \mu \mathrm{g} / \mathrm{ml})$ in the presence of WT, PLC $\gamma 2^{-/-}$, or $\beta$ catcKo MDSCs isolated from tumor-bearing mice treated with anti-Dkk1 or IgG antibodies. Different CFSE-labeled splenocyte/MDSC ratios were used (1:10, 1:5, and 1:1). Proliferation of $\mathrm{CD}^{+} \mathrm{T}$ cells, in terms of CFSE dilution, was determined by FACS. Data are expressed as the percentage of proliferation of stimulated $\mathrm{CD}^{+} \mathrm{CFSE}^{+} \mathrm{T}$ cells. Each experiment was performed in triplicate.

Western blotting. MDSCs isolated from the bone marrow of tumor-bearing mice were lysed with RIPA buffer $(50 \mathrm{mM}$ Tris-HCl, pH 7.4, 150 mM NaCl, 1\% NP-40, 0.1\% SDS, $0.5 \%$ sodium deoxycholate, $1 \mathrm{mM}$ EDTA, and 10\% glycerol) supplemented with protease and phosphatase inhibitor cocktail (Thermo Fisher Scientific). Equal amounts of total protein lysates were subjected to $8 \%$ SDS-PAGE gel and transferred to PVDF membranes. Membranes were blocked in 5\% BSA in PBS/Tween-20 for $1 \mathrm{~h}$, and then probed with the appropriate specific primary antibody overnight at $4^{\circ} \mathrm{C}$. Membranes were washed and incubated for $2 \mathrm{~h}$ at room temperature with secondary antibody-conjugated with peroxidase. Results were visualized by chemiluminescence detection using a SuperSignal West Dura Extended Duration Substrate (Thermo Fisher Scientific). An antibody against total $\beta$ catenin was obtained from Cell Signaling Technology. Equal loading was assessed using anti- $\beta$-actin from Sigma-Aldrich.
Semi-quantifications of protein were determined using GeneTools software (Syngene).

IHC analysis. Tissue sections from LLC and B16 s.c. tumors or pancreas from animals that express an oncogenic form of RAS and develop spontaneous pancreatic cancer (KPC mice: p48-CRE/Lox-stop-lox KrasG12D/+ p53flox/+) were used for Dkk1 IHC analyses. Paraffin sections were deparaffinized in serial changes with decreasing ethanol (100, 95, 70, and $50 \%$, deionized with $\mathrm{H}_{2} \mathrm{O}$, and rinsed in PBS. Tissue sections were submerged in citrate buffer $(10 \mathrm{mM}$ sodium citrate and $0.05 \%$ Tween $20, \mathrm{pH} 6$ ), and antigen retrieval was performed in a decloaking chamber (Biocare Medical). The sections were washed in running deionized water and rinsed in PBS, blocked for $30 \mathrm{~min}$ at room temperature in blocking buffer (5\% normal goat serum, BSA, and PBS), and stained with anti-Dkk1 primary antibody (Santa Cruz Biotechnology, Inc.; clone H-120; 1:100) diluted in antibody diluent overnight at $4^{\circ} \mathrm{C}$. The day after washing, a biotinylated secondary antibody was applied to the slides for $30 \mathrm{~min}$ at room temperature in a humidified chamber, after SA-HRP incubation (Perkin Elmer) for an additional $30 \mathrm{~min}$. Staining was developed using DAB after $3 \mathrm{~min}$ of incubation. The tissue sections were mounted on coverslips with Vectashield Hard Mounting Media (Vector Labs).

Pancreatic cancer TMA cohort and analysis. TMA studies were conducted on a patient cohort constructed from 60 cases of invasive pancreatic ductal adenocarcinoma diagnosed at the Department of Pathology, Washington University (Mitchem et al., 2013; Zhu et al., 2014). Patients had not received neoadjuvant therapy, and they underwent pancreaticoduodenectomy, which was typically followed by adjuvant chemotherapy.The ethical committee at the Washington University School of Medicine approved this study. To assemble TMAs, clearly defined areas of tumor tissue were demarked on a slide with a fresh tissue section from the paraffin block. Two biopsies $(1.0 \mathrm{~mm}$ diam) were taken from each donor paraffin block corresponding to the marked area. For immunohistochemical analyses, 4.0-mm paraffin sections were used. Fully automated image acquisition was used for the results presented in this study. The Aperio ScanScope XT Slide Scanner (Aperio Technologies) system was used to capture whole slide digital images with a $20 \times$ objective. Slides were de-arrayed to visualize individual cores using Spectrum software (Aperio). CD $15^{+}$leukocytes were quantitated using a modified nuclear/lymphocyte algorithm in the spectrum software, and Dkk1 was quantitated as total pixel density. The highest value to each TMA spot was assigned to each patient.

Real-time PCR. Total RNA was extracted with TRIzol (Invitrogen) and quantified on a ND-1000 spectrophotometer (NanoDrop Technologies). The cDNA was synthesized with $1 \mu \mathrm{g}$ RNA using RNA to cDNA EcoDry Premix (oligo dT) 
RT-PCR kit from EMD Millipore. The amount of Dkk1 was determined using Power SYBR Green mix on 7300 Real-Time PCR System (Applied Biosystems). Cyclophilin mRNA was used as internal control. Specific primers for mice were as follows: Dkk1, 5'-CTCATCAATTCCAACGCG ATCA-3' and 5'-GCCCTCATAGAGAACTCCCG-3'; Cyclophilin, 5'-AGCATACAGGTCCTGGCATC-3' and 5'-TTCACCTTCCCAAAGACCAC-3'; TCF4, 5'-CGA AAAGTTCCTCCGGGTTTG-3' and 5'-CGTAGCCGG GCTGATTCAT-3'; LEF1， 5'-TGTTTATCCCATCAC GGGTGG- $3^{\prime}$ and $5^{\prime}$-CATGGAAGTGTCGCCTGACAG$3^{\prime}$; Axin2, 5'-ATGTGTGGATACGCTGGACTT-3' and 5'-TTCTTGATGCCATCTCGTATG-3'; LRP5, 5'-AAT CAACAAGCCACCCTCTG-3' and 5'-GGCTCCACC AACATACTCGT-3', LRP6, 5'-ACCCTGCAGCACTGA TGTCT-3' and 5'-GTTCTCCTCCGCTGACAAGT-3'.

Specific primers for human MDSC were as follows:TCF4, 5'-CAAGCACTGCCGACTACAATA- ${ }^{\prime}$ and $5^{\prime}$-CCAGGC TGATTCATCCCACTG-3'; LEF1, 5' -AATGCACGTGAA GCCT- $3^{\prime}$ and $5^{\prime}$-GAATCTGGTTGATAGCTGC-3'.

Relative quantification of transcription was calculated as the power of the difference between amplification of the target gene and amplification of Cyclophilin (i.e., 2 -[Ct target gene - Ct cyclophilin], where Ct represents threshold cycle).

Statistical analysis. Experiments were done in triplicate and analyzed using the Student's $t$ test. In calculating twotailed significance levels for equality of means, equal variances were assumed for the two populations. In some experiments, analysis of variance (ANOVA), including the Bonferroni's multiple-comparison test, was used. Results were considered significant at $\mathrm{P}<0.05$.

\section{ACKNOWLEDGMENTS}

We gratefully thank Amgen for providing the anti-Dkk1 antibody. The authors thank Deborah V. Novack from Washington University in St. Louis for helpful discussion.

We thank the Washington University Bright Institute and Molecular Imaging Center (P50 CA94056ADD) and The Washington University Musculoskeletal Research Center, funded by National Institutes of Health (NIH) grant P30 AR057235. This work was also funded by NIH grants R01 AR053628 and AR066551 to R. Faccio and 5 R01CA151518 to S.A. Stewart, Shriners Hospital grant 85100 to R. Faccio, the American Society for Bone and Mineral Research Gap grant to R. Faccio, Siteman Cancer Center grant to R. Faccio and S.A. Stewart. D.B. Bumpass was supported by the Young Investigator Translational Research Grant from the North American Spine Society. The work was supported in part by the Alvin J. Siteman Cancer Research Fund at Washington University in St. Louis, MO (S.A. Stewart), American Cancer Society Research Scholar Award to S.A. Stewart, KL2 TR000450 to A. Wang-Gillam, and 2R01 CA097250 to K. Weilbaecher. D.G.D would like to acknowledge grants from the Pancreatic Cancer Action Network and Lustgarten foundation.

Author contributions: L. D'Amico, A.-H. Capietto, and R. Faccio designed research; L. D'Amico, S. Mahajan., A.-H. Capietto, Z. Yang, B. Ricci, M. Meyer, A. Zamani, and X. Su performed research; D.G. DeNardo, A. Wang-Gillam, K. Weilbaecher and D.B. Bumpass provided patient samples and performed analysis, L. D'Amico, A.-H. Capietto, S. Mahajan, Z. Yang, and R. Faccio analyzed and discussed the data; L. D'Amico and R.F. wrote the paper. S.A. Stewart and D.G. DeNardo participated in experimental design, data analysis, and paper revision.

The authors declare no competing financial interests.
Submitted: 8 June 2015

Accepted: 24 February 2016

\section{REFERENCES}

Barcellos-Hoff, M.H., D. Lyden, and T.C. Wang. 2013. The evolution of the cancer niche during multistage carcinogenesis. Nat. Rev. Cancer. 13:511518. http://dx.doi.org/10.1038/nrc3536

Bindea, G., B. Mlecnik, M. Tosolini, A. Kirilovsky, M. Waldner, A.C. Obenauf, H. Angell, T. Fredriksen, L. Lafontaine, A. Berger, et al. 2013. Spatiotemporal dynamics of intratumoral immune cells reveal the immune landscape in human cancer. Immunity. 39:782-795. http://dx .doi.org/10.1016/j.immuni.2013.10.003

Capietto, A.H., S. Kim, D.E. Sanford, D.C. Linehan, M. Hikida, T. Kumosaki, D.V. Novack, and R. Faccio. 2013. Down-regulation of PLC $\gamma 2-\beta-$ catenin pathway promotes activation and expansion of myeloid-derived suppressor cells in cancer. J. Exp. Med. 210:2257-2271. http://dx.doi.org /10.1084/jem.20130281

Fowler, J.A., G.R. Mundy, S. T. Lwin, and C.M. Edwards. 2012. Bone marrow stromal cells create a permissive microenvironment for myeloma development: a new stromal role for Wnt inhibitor Dkk1. Cancer Res. 72:2183-2189. http://dx.doi.org/10.1158/0008-5472.CAN-11-2067

Gabitass, R.F., N.E. Annels, D.D. Stocken, H.A. Pandha, and G.W. Middleton. 2011. Elevated myeloid-derived suppressor cells in pancreatic, esophageal and gastric cancer are an independent prognostic factor and are associated with significant elevation of the Th2 cytokine interleukin-13. Cancer Immunol. Immunother. 60:1419-1430. http://dx.doi.org/10.1007 /s00262-011-1028-0

Gabrilovich, D.I., M.P. Velders, E.M. Sotomayor, and W.M. Kast. 2001. Mechanism of immune dysfunction in cancer mediated by immature Gr-1+ myeloid cells. J. Immunol. 166:5398-5406. http://dx.doi.org/10 .4049/jimmunol.166.9.5398

Gabrilovich, D.I., S. Ostrand-Rosenberg, and V. Bronte. 2012. Coordinated regulation of myeloid cells by tumours. Nat. Rev. Immunol. 12:253-268. http://dx.doi.org/10.1038/nri3175

Galon, J., A. Costes, F. Sanchez-Cabo, A. Kirilovsky, B. Mlecnik, C. LagorcePagès, M. Tosolini, M. Camus, A. Berger, P. Wind, et al. 2006. Type, density, and location of immune cells within human colorectal tumors predict clinical outcome. Science. 313:1960-1964. http://dx.doi.org/10 $.1126 /$ science. 1129139

Hamanishi, J., M. Mandai, M. Iwasaki, T. Okazaki, Y. Tanaka, K. Yamaguchi, T. Higuchi, H. Yagi, K. Takakura, N. Minato, et al. 2007. Programmed cell death 1 ligand 1 and tumor-infiltrating $\mathrm{CD}^{+} \mathrm{T}$ lymphocytes are prognostic factors of human ovarian cancer. Proc. Natl. Acad. Sci. USA. 104:3360-3365. http://dx.doi.org/10.1073/pnas.0611533104

Li, J., I. Sarosi, R.C. Cattley, J. Pretorius, F.Asuncion, M. Grisanti, S. Morony, S. Adamu, Z. Geng, W. Qiu, et al. 2006. Dkk1-mediated inhibition of Wnt signaling in bone results in osteopenia. Bone. 39:754-766. http://dx.doi .org/10.1016/j.bone.2006.03.017

Liu, Y., W. Tang, L. Xie, J. Wang, Y. Deng, Q. Peng, L. Zhai, S. Li, and X. Qin. 2014. Prognostic significance of dickkopf-1 overexpression in solid tumors: a meta-analysis. Tumour Biol. 35:3145-3154. http://dx.doi.org /10.1007/s13277-013-1411-x

MacDonald, B.T., K. Tamai, and X. He. 2009. Wnt/beta-catenin signaling: components, mechanisms, and diseases. Dev. Cell. 17:9-26. http://dx.doi .org/10.1016/j.devcel.2009.06.016

Mace, T.A., Z. Ameen, A. Collins, S. Wojcik, M. Mair, G.S. Young, J.R. Fuchs, T.D. Eubank, W.L. Frankel, T. Bekaii-Saab, et al. 2013. Pancreatic cancerassociated stellate cells promote differentiation of myeloid-derived suppressor cells in a STAT3-dependent manner. Cancer Res. 73:30073018. http://dx.doi.org/10.1158/0008-5472.CAN-12-4601

Mahmoud, S.M., E.C. Paish, D.G. Powe, R.D. Macmillan, M.J. Grainge, A.H. Lee, I.O. Ellis, and A.R. Green. 2011. Tumor-infiltrating CD8+ 
lymphocytes predict clinical outcome in breast cancer. J. Clin. Oncol. 29:1949-1955. http://dx.doi.org/10.1200/JCO.2010.30.5037

Mitchem, J.B., D.J. Brennan, B.L. Knolhoff, B.A. Belt, Y. Zhu, D.E. Sanford, L. Belaygorod, D. Carpenter, L. Collins, D. Piwnica-Worms, et al. 2013. Targeting tumor-infiltrating macrophages decreases tumor-initiating cells, relieves immunosuppression, and improves chemotherapeutic responses. Cancer Res. 73:1128-1141. http://dx.doi.org/10.1158/0008 -5472.CAN-12-2731

Mundy-Bosse, B.L., G.S. Young, T. Bauer, E. Binkley, M. Bloomston, M.A. Bill, T. Bekaii-Saab, W.E. Carson III, and G.B. Lesinski. 2011. Distinct myeloid suppressor cell subsets correlate with plasma IL-6 and IL-10 and reduced interferon-alpha signaling in $\mathrm{CD}^{+} \mathrm{T}$ cells from patients with GI malignancy. Cancer Immunol. Immunother. 60:1269-1279. http://dx doi.org/10.1007/s00262-011-1029-z

Pinzone, J.J., B.M. Hall, N.K. Thudi, M. Vonau, Y.W. Qiang, T.J. Rosol, and J.D. Shaughnessy Jr. 2009. The role of Dickkopf-1 in bone development, homeostasis, and disease. Blood. 113:517-525. http://dx.doi.org/10 1182/blood-2008-03-145169

Porembka, M.R., J.B. Mitchem, B.A. Belt, C.S. Hsieh, H.M. Lee, J. Herndon, W.E. Gillanders, D.C. Linehan, and P. Goedegebuure. 2012. Pancreatic adenocarcinoma induces bone marrow mobilization of myeloid-derived suppressor cells which promote primary tumor growth. Cancer Immunol. Immunother. 61:1373-1385. http://dx.doi.org/10.1007/s00262-011 $-1178-0$

Räsänen, K., and A.Vaheri. 2010.Activation of fibroblasts in cancer stroma. Exp Cell Res. 316:2713-2722.http://dx.doi.org/10.1016/j.yexcr.2010.04.032

Schreiber, R.D., L.J. Old, and M.J. Smyth. 2011. Cancer immunoediting: integrating immunity's roles in cancer suppression and promotion. Science. 331:1565-1570. http://dx.doi.org/10.1126/science.1203486

Tian, E., F. Zhan, R. Walker, E. Rasmussen, Y. Ma, B. Barlogie, and J.D. Shaughnessy Jr. 2003. The role of the Wnt-signaling antagonist DKK1 in the development of osteolytic lesions in multiple myeloma. N. Engl.J. Med. 349:2483-2494. http://dx.doi.org/10.1056/NEJMoa030847

Trikha, P., and W.E. Carson III. 2014. Signaling pathways involved in MDSC regulation. Biochim. Biophys. Acta. 1846:55-65. http://dx.doi.org/10 .1016/j.bbcan.2014.04.003
Weilbaecher, K.N., T.A. Guise, and L.K. McCauley. 2011. Cancer to bone: a fatal attraction. Nat. Rev. Cancer. 11:411-425. http://dx.doi.org/10.1038 $/ \operatorname{nrc} 3055$

Yaccoby, S., W. Ling, F. Zhan, R. Walker, B. Barlogie, and J.D. Shaughnessy Jr. 2007. Antibody-based inhibition of DKK1 suppresses tumor-induced bone resorption and multiple myeloma growth in vivo. Blood. 109:21062111. http://dx.doi.org/10.1182/blood-2006-09-047712

Yamabuki, T., A. Takano, S. Hayama, N. Ishikawa, T. Kato, M. Miyamoto, T. Ito, H. Ito, Y. Miyagi, H. Nakayama, et al. 2007. Dikkopf-1 as a novel serologic and prognostic biomarker for lung and esophageal carcinomas. Cancer Res. 67:2517-2525. http://dx.doi.org/10.1158/0008-5472 .CAN-06-3369

Yang, C., J.L. Davis, R. Zeng, P.Vora, X. Su, L.I. Collins, S.Vangveravong, R.H. Mach, D. Piwnica-Worms, K.N. Weilbaecher, et al. 2013. Antagonism of inhibitor of apoptosis proteins increases bone metastasis via unexpected osteoclast activation. Cancer Discov. 3:212-223. http://dx.doi.org/10 .1158/2159-8290.CD-12-0271

Zhang,W., and M.T.Drake. 2012. Potential role for therapies targeting DKK1, LRP5, and serotonin in the treatment of osteoporosis. Curr. Osteoporos. Rep. 10:93-100. http://dx.doi.org/10.1007/s11914-011-0086-8

Zhang, K., S. Kim, V. Cremasco, A.C. Hirbe, L. Collins, D. Piwnica-Worms, D.V. Novack, K. Weilbaecher, and R. Faccio. 2011. CD8+ T cells regulate bone tumor burden independent of osteoclast resorption. Cancer Res. 71:4799-4808. http://dx.doi.org/10.1158/0008-5472.CAN-10-3922

Zheng, Y., D. Basel, S.O. Chow, C. Fong-Yee, S. Kim, F. Buttgereit, C.R. Dunstan, H. Zhou, and M.J. Seibel. 2014. Targeting IL-6 and RANKL signaling inhibits prostate cancer growth in bone. Clin. Exp. Metastasis. 31:921-933. http://dx.doi.org/10.1007/s10585-014-9680-3

Zhu, Y., B.L. Knolhoff, M.A. Meyer, T.M. Nywening, B.L. West, J. Luo, A Wang-Gillam, S.P.Goedegebuure,D.C.Linehan, and D.G.DeNardo. 2014. CSF1/CSF1R blockade reprograms tumor-infiltrating macrophages and improves response to T-cell checkpoint immunotherapy in pancreatic cancer models. Cancer Res. 74:5057-5069. http://dx.doi.org/10.1158 /0008-5472.CAN-13-3723 